\title{
Management Control System Description
}

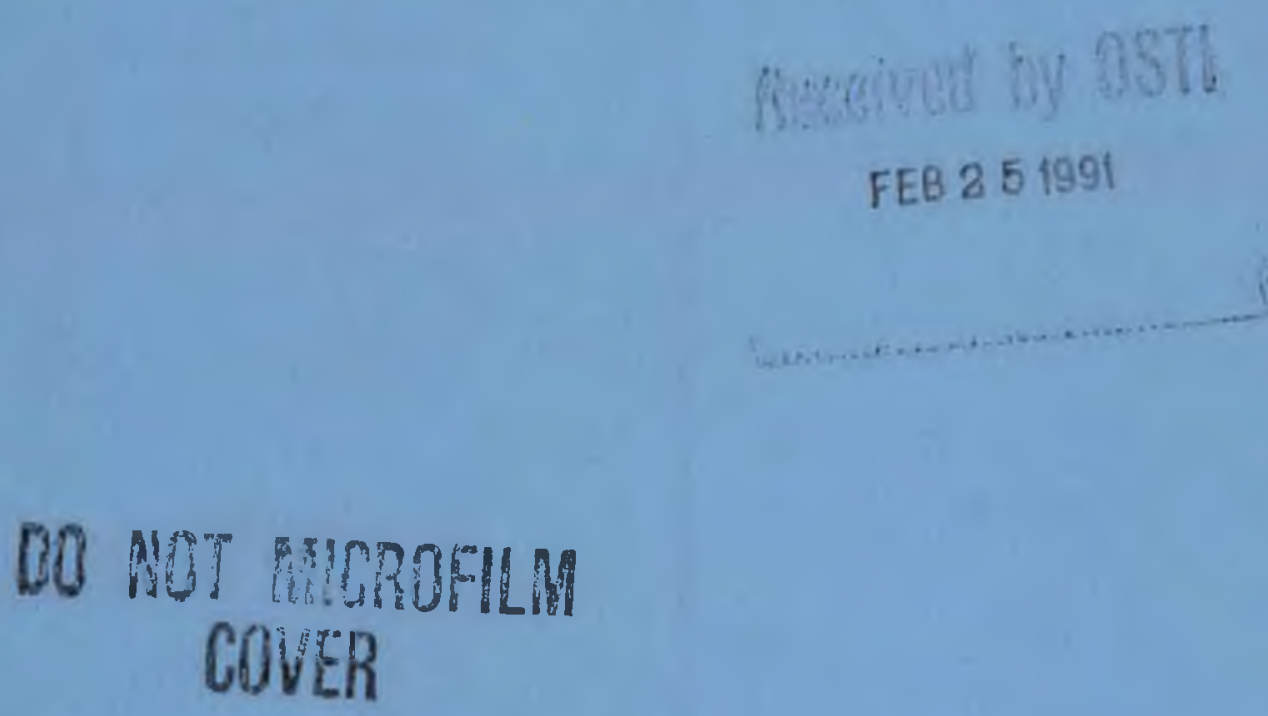

Prepared for the U.S. Department of Energy Assistant Secretary for Management and Administration

(2) Westinghouse

Hanford Operations and Engineering Contractor for the U.S. Department of Energy under Contract DE-AC06-87RL10930

Approved for Public Release 


\section{DISCLAIMER}

This report was prepared as an account of work sponsored by an agency of the United States Government. Neither the United States Government nor any agency Thereof, nor any of their employees, makes any warranty, express or implied, or assumes any legal liability or responsibility for the accuracy, completeness, or usefulness of any information, apparatus, product, or process disclosed, or represents that its use would not infringe privately owned rights. Reference herein to any specific commercial product, process, or service by trade name, trademark, manufacturer, or otherwise does not necessarily constitute or imply its endorsement, recommendation, or favoring by the United States Government or any agency thereof. The views and opinions of authors expressed herein do not necessarily state or reflect those of the United States Government or any agency thereof. 


\section{DISCLAIMER}

Portions of this document may be illegible in electronic image products. Images are produced from the best available original document. 


\section{LEGAL DISCLAIMER}

This report was prepared as an account of work sponsored by an agency of the United States Government. Neither the United States Government nor any agency thereof, nor any of their employees, nor any of their contractors, subcontractors or their employees, makes any warranty, express or implied, or assumes any legal liability or responsibility for the accuracy, completeness, or any third party's use or the results of such use of any information, apparatus, product, or process disclosed, or represents that its use would not infringe privately owned rights. Reference herein to any specific commercial product, process, or service by trade name, trademark, manufacturer, or otherwise, does not necessarily cuicititute $x$ imaly its endorsement, recommendation, or favoring by the United Staies Government or any agoricy thereof or its contractors or subcontractors. The views and opinions of authors expressed herein do not necessarily state or reflect those of the United States Government or any agency thereof.

This report has been reproduced from the best available copy. Available in paper copy and microfiche.

The U.S. Deparrment of Energy and its contractors can obtain copies of this report from:

Office of Scientific and Technical Information

P.O. Box 62

Oak Ridge, TN 37831

(615) $576-8401$

This report is publicly available from:

National Technical Information Service

5285 Port Royal Road

Springfield, VA 22161

(703) 487-4650

Printed in the United States of America

DISCLM-1.CHP (10-90) 
WHC-EP--0388

DE91 007915

\title{
Management Control System Description
}

\author{
P. J. Bence
}

Date Published

October 1990

Prepared for the U.S. Department of Energy

Assistant Secretary for Management and Administration

(2)

Westinghouse

P.O. Box 1970

Hantord Company Richland, Washington 99352

Hantord Operations and Engineering Contractor for the

U.S. Department of Energy under Contract DE-AC06-87RL10930

Approved for Public Release 
WHC-EP-0388

This page intentionally left blank.

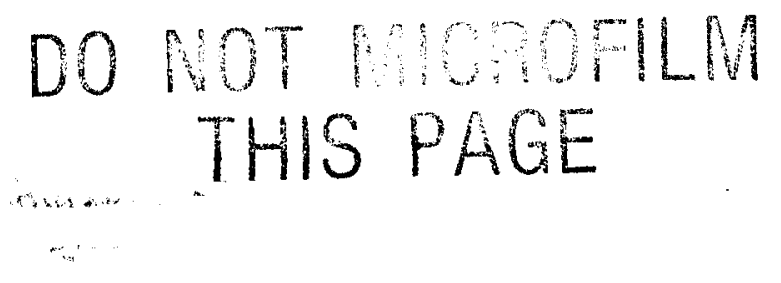

iT- 
WHC-EP-0388

Document Title: Management Control System Description

Prepared by:

Approved by:

1

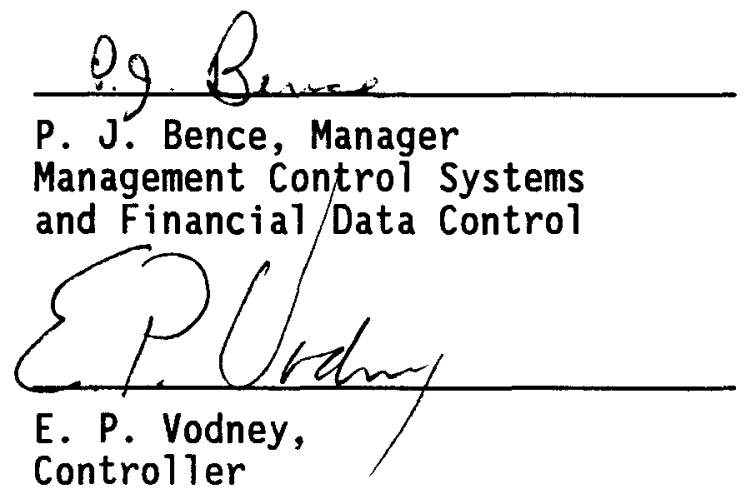

Controller

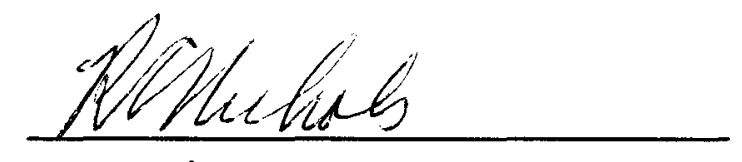

R. C. Nichols President
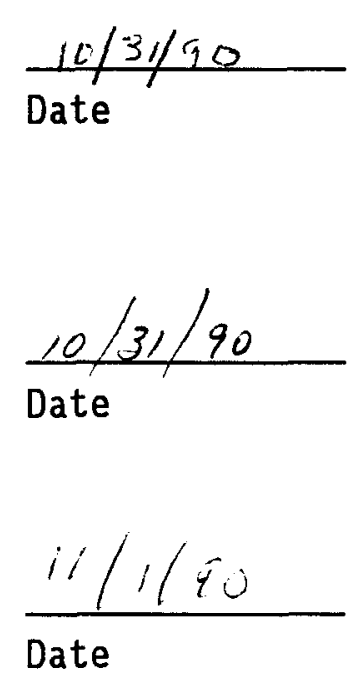

i ii/iv 
WHC-EP-0388

This page intentionally left blank.

\section{DO NOT MOCOOFLM THIS PAGE}


WHC-EP-0388

CONTENTS

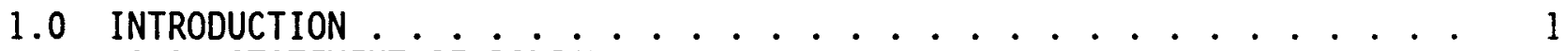

1.1 STATEMENT OF POLICY . . . . . . . . . . . . . . . . 1

1.2 PURPOSE ........................ 1

2.0 OVERVIEW OF THE MANAGEMENT CONTROL SYSTEM . . . . . . . . . . 3

2.1 MANAGEMENT CONTROL SYSTEM APPLICATION ............ 5

2.2 TYPES OF WORK .................. 5

2.2.1 Operating Programs .............. 5

2.2 .2 Projects ................ . . 5 5

2.2.3 Management Control System

Requirement Application . . . . . . . . . 6

2.3 ORGANIZATION .................. . . . 6

2.4 PLANNING AND BUDGETING . . . . . . . . . . . . . . 11

2.5 ACCOUNTING . . . . . . . . . . . . . . . . 11

2.6 ANALYSIS AND REPORTING . . . . . . . . . . . . . 11

2.7 CHANGE CONTROL . . . . . . . . . . . . . . . 12

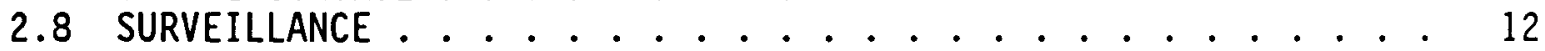

3.0 ORGANIZATION . . . . . . . . . . . . . . . . . . . . . . . 13

3.1 PROGRAM OR PROJECT MANAGER $\ldots 15$

3.2 PROGRAM ADMINISTRATION OR PROJECT CONTROL ......... 15

3.3 END FUNCTION WORK BREAKDOWN STRUCTURE LEVEL ......... 15

3.4 ACTIVITY WORK BREAKDOWN STRUCTURE LEVEL . . . . . . . . . . 16

3.5 COST ACCOUNT WORK BREAKDOWN STRUCTURE LEVEL . . . . . . . . . 16

3.6 PERFORMING ORGANIZATIONS . . . . . . . . . . . . . . . . 17

3.7 MANAGEMENT CONTROL SYSTEM ORGANIZATION . . . . . . . . . . . 17

4.0 PLANNING AND BUDGETING . . . . . . . . . . . . . . . . . 19

4.1 ESTIMATING . . . . . . . . . . . . . . . . . . . . 19

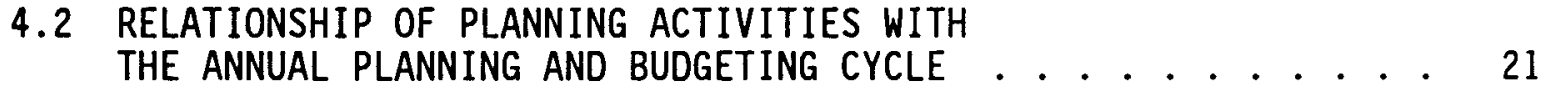

4.3 BASELINES ....................... 21

4.4 PROJECT MANAGEMENT PLAN . . . . . . . . . . . . . 23

4.5 PROJECT BUDGET BASELINE ELEMENTS . . . . . . . . . . . . . . 23

4.5.1 Contract Budget Base ... . . . . . . . . . . 23

4.5.2 Performance Measurement Basel ine . . . . . . . . 25

4.5.3 Management Reserve ... . . . . . . . . . . 25

4.5.4 Undistributed Budget ............... 25

4.6 SCHEDULE HIERARCHY . . . . . . . . . . . . . . . . 25

4.6.1 Schedule Hierarchy Description .. . . . . . . . . 25

4.6.2 Schedule Levels.............. 26

4.7 COST ACCOUNT AUTHORIZATION . . . . . . . . . . . . . . . . 28

4.8 COST ACCOUNT PLAN . . . . . . . . . . . . . . . . . . 30

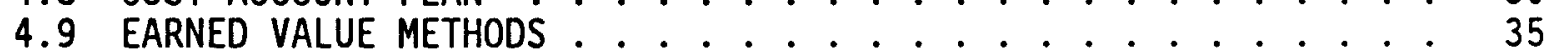

4.10 WORK AUTHORIZATION . . . . . . . . . . . . . 36

4.11 WORK COMPLETION ................. . . 37

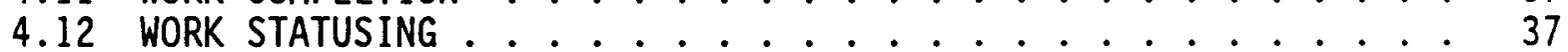




\section{CONTENTS (cont)}

5.0 ACCOUNTING . . . . . . . . . . 39

5.1 DATABASE DESCRIPTION ............... 39

5.1.1 Financial Data System ............. . 39

5.2 ELEMENTS OF COST ................ 39

5.3 ORGANIZATION CODE STRUCTURE .............. . 41

5.4 COST ELEMENT STRUCTURE . . . . . . . . . . . . . . 41

5.5 CHARGE CODE STRUCTURE ................ 42

5.6 CLASSIFICATION OF COSTS . . . . . . . . . . . . . . . . . 44

5.6.1 Direct Costs ................ . 44 44

5.6.2 Indirect costs . . . . . . . . . . . . . 44 44

5.7 MATERIAL COST CONTROL ............... . 49

5.8 PURCHASE ORDER SYSTEM ................ . . 49

6.0 ANALYSIS AND REPORTING ................... 51

6.1 VARIANCE ANALYSIS .................. . . 51

6.1.1 Variance of Concern .............. . 51

6.1.2 Variance Thresholds ............ . 54

6.2 PREPARATION OF VARIANCE ANALYSIS REPORTS . . . . . . . . . . 54

6.3 PRICE AND USAGE VARIANCE . . . . . . . . . . . . . 55

6.4 ESTIMATE AT COMPLETION . . . . . . . . . . . . . . 55

6.5 CUSTOMER REPORTING . . . . . . . . . . . . . 56

6.6 TREND ANALYSIS ................... . . 56

6.7 FUNDS MANAGEMENT . . . . . . . . . . . . . 57

7.0 CHANGE CONTROL . . . . . . . . . . . . . . . . . 61

7.1 CHANGE IDENTIFICATION AND ANALYSIS ............ 61

7.2 CHANGE IMPLEMENTATION ................... . . . . . 64

7.3 MANAGEMENT CONTROL SYSTEM GROUND RULES . . . . . . . . . . . . 64

7.4 PRODUCTIVITY AND COST EFFECTIVENESS PROGRAM . . . . . . . . 66

8.0 SURVEIllance . . . . . . . . . . . . . . . 67

9.0 REFERENCES ....................... 69 APPENDIX:

A. Glossary of Terms ................ . . A-1 
WHC-EP-0388

\section{LIST OF FIGURES}

2-1 Management Control system Flow ............... 4

2-2 Management Control System Flow Chart . . . . . . . . . . . . 6

3-1 Contract Work Breakdown Structure

and Responsibility Assignment Matrix. . . . . . . . . . . . 14

4-1 Westinghouse Hanford Work Planning and Authorization Process ... . . . . . . . . . . 20

4-2 Annual Cyclical Planning and Budgeting Process . . . . . . . 22

4-3 Budget Baseline Element Relationships ............ 24

4-4 Schedule Hierarchy . . . . . . . . . . . . . . . . . . 27

4-5 Example of a Milestone Control Log . . . . . . . . . . . . . 29

4-6 Cost Account Authorization Form . . . . . . . . . . . . 31

4-7 Cost Account Plan Work Sheet Form . . . . . . . . . . 32

4-8 Example of Cost Account Plan ............... 33

5-1 Financial Data System Interfaces . . . . . . . . . . 40

5-2 Work Breakdown Structure Charge Codes . . . . . . . . . . 43

5-3 Rate Accumulation Example . . . . . . . . . . . . . 47

5-4 Rate Evaluation Process Flow ................. 48

6-1 Performance Analysis and Reporting Process .......... 52

6-2 Variances as a Product of the Management Control System . . . . . 53

6-3 Example of Expense--Budget and Funds Log . . . . . . . . . . 59

7-1 Change Control System .................. 62

7-2 Example of Change Request Form . . . . . . . . . . . . 6 63

7-3 Sample Change-Control Log .............. 65

8-1 Surveillance Process .................. 68 
WHC-EP-0388

\section{LIST OF TABLES}

2-1 Management Control System Application . . . . . . . . . . . . . 9 
WHC-EP-0388

\section{MANAGEMENT CONTROL SYSTEM DESCRIPTION}

\subsection{INTRODUCTION}

This Management Control System (MCS)* Description describes the processes used to manage the cost and schedule of work performed by Westinghouse Hanford Company (Westinghouse Hanford) for the U.S. Department of Energy, Richland Operations Office (DOE-RL), Richland, Washington.

\subsection{STATEMENT OF POLICY}

Westinghouse Hanford will maintain and use formal cost and schedule management control systems, as presented in this document, in performing work for the DOE-RL. This MCS description is a controlled document and will be modified or updated as required. This document must be approved by the $\mathrm{DOE}-\mathrm{RL}$; thereafter, any significant change will require DOE-RL concurrence.

\subsection{PURPOSE}

Westinghouse Hanford is the DOE-RL operations and engineering contractor at the Hanford Site. Activities associated with this contract

(DE-AC06-87RL10930) include operating existing plant facilities, manaing defined projects and programs, and planning future enhancements. This document is designed to comply with Section I-13 of the contract by providing a description of Westinghouse Hanford's cost and schedule control systems used in manaing the above activities.

The Westinghouse Hanford MCS is designed to provide a consistent approach for managing and controlling all DOE-RL assigned work. This document presents the principles and general requirements of the system. Specific procedures implementing these principles and requirements are contained in manual WHC-CM-2-5, Management Control System (WHC 1990). The U.S. Department of Energy (DOE) may impose additional requirements on individual programs and/or projects that result in unique procedures that are not featured in the MCS manual. The role of an integrating contractor on a multicontractor project is an example of such additional work requirements. These additional requirements are to be documented in a project management plan and implemented in unique procedures.

*Appendix $A$ contains a list of abbreviations and document-specific terms used in this MCS Description. 
WHC-EP-0388

This page intentionally left blank.

$$
\begin{aligned}
& \text { DO WOT WOROELM } \\
& \text { THIS PAGE }
\end{aligned}
$$




\subsection{OVERVIEW OF THE MANAGEMENT CONTROL SYSTEM}

Managerial activity is focused on achieving technical goals within agreed-to budgets and schedules. These managerial activities are governed by the MCS, as set forth in this system description. The following sections present a brief introduction to the MCS by explaining the system's objectives, its application, and how its subsystems (or processes) relate to the annual planning and budgeting cycle.

The primary purpose of the MCS is to provide the program and/or project offices and the responsible organizations with consistent management policies for planning, authorizing, and controlling their work so that it can be completed as defined, on schedule, and within budget. The six MCS activities--work organization and definition, work planning and authorization, work performance and measurement, performance analysis and reporting, change control, and surveillance--are shown in Figure 2-1. Adherence to the six major activities facilitates the following actions:

- Ensure that planning and execution of work are accomplished at the proper organizational levels.

- Ensure that performance of work is authorized only after it is planned and approved by proper authority.

- Assign specific responsibility for the work identified at the appropriate level within the work breakdown structure (WBS) to a responsible organization.

- Schedule the work using meaningful milestones to facilitate planning and provide traceability from the level of the WBS where work is accomplished to the program or project summary level.

- Support detailed and integrated planning to a standard format using a WBS.

- Provide a method for measuring work performance against actual costs incurred and work scheduled.

- Provide for analysis of significant deviations from the baseline $\mathrm{plan}$ by the organization responsible for execution of the work.

- Provide for the reporting of performance against the baseline plan to Westinghouse Hanford management and the DOE-RL.

- Provide a basis for identifying, evaluating, and determining subsequent disposition of approved changes. 


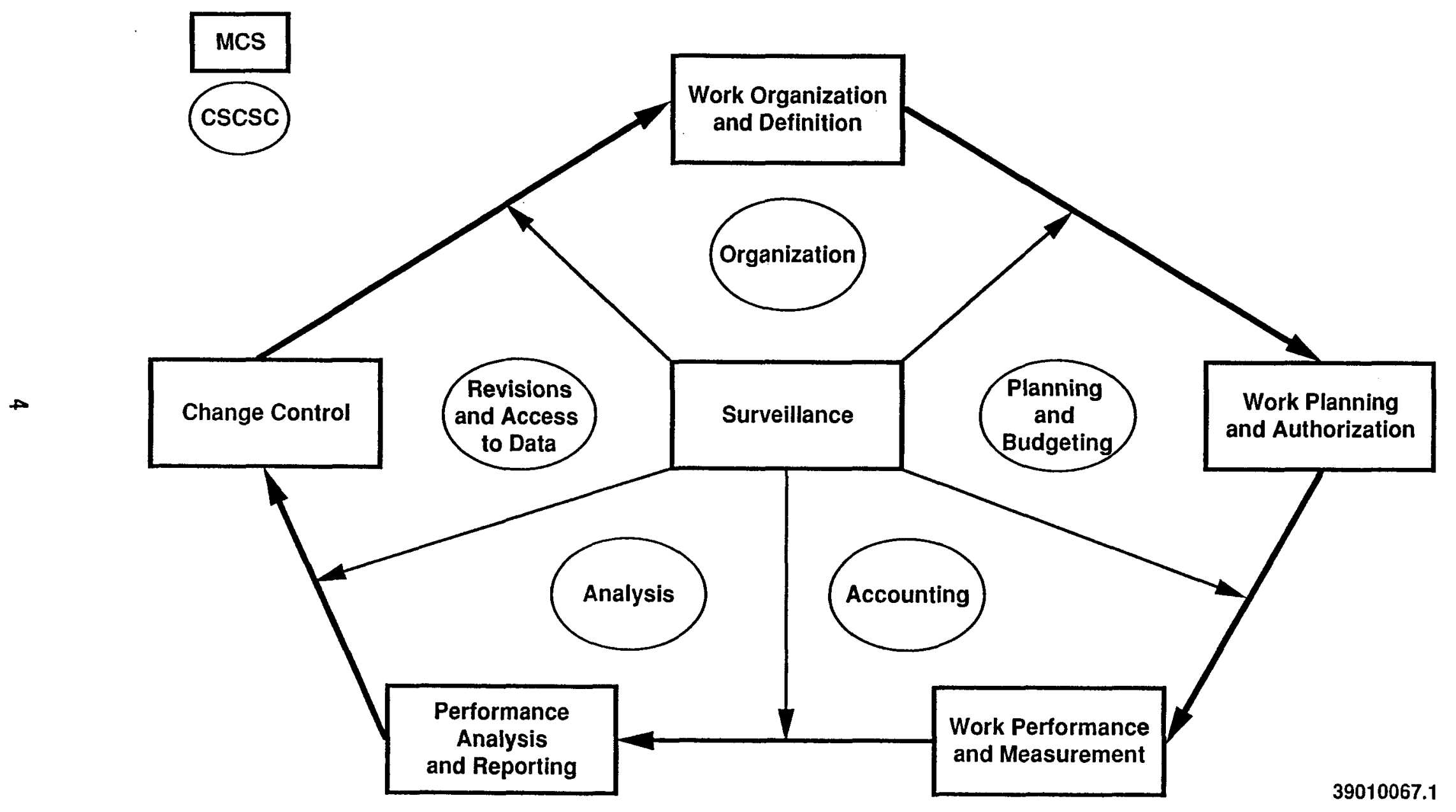

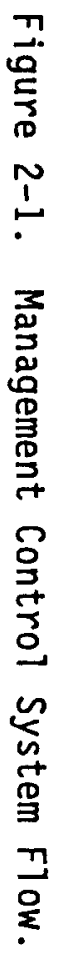


- Provide for periodic surveillance to ensure that all elements of the system are properly maintained.

- Provide that authorized work is in agreement with authorized funding and baseline documents received from the DOE-RL.

\subsection{MANAGEMENT CONTROL SYSTEM APPLICATION}

The MCS guidelines should be flexible enough to meet the needs of both the project and the program environments. In addition, the system should adapt itself to changing management needs. The MCS applies to all work performed at Westinghouse Hanford by all programs and projects regardless of funding type. The MCS process is depicted in the MCS flow chart (Figure 2-2).

\subsection{TYPES OF WORK}

The operation and management of the Hanford Site includes various types of work, each with its own unique work breakdown and planning requirements. The MCS is designed to meet the requirements of all work types by applying controls with varying degrees of rigor depending on the classification of the work. When applied to a major system acquisition (MSA), a major project (MP), or other specific work designated by the U.S. Secretary of Energy, the MCS will satisfy Cost and Schedule Control System's Criteria (CSCSC) as specified in DOE Order 2250.1C (DOE 1988). Other projects (those not required to meet CSCSC) and operating programs will be managed using the same MCS but without some of the formal reporting requirements and documentation. The following paragraphs will explain the differences in these types of work and highlight the MCS application to each.

\subsubsection{Operating Programs}

At Westinghouse Hanford, each program organization is tied closely to the respective DOE-RL program organization, and each program is an organized set of activities directed toward a specific purpose or proposed in support of an assigned mission area. These programs are typically made up of technologybased activities and supporting activities. Program work definition is based on requirements established in DOE long-range plans, Hanford Site-specific long-range plans, and program-specific program plans and program management plans. These plans are a result of ongoing cyclic planning and review.

\subsubsection{Projects}

Projects are unique major efforts that are individually planned, approved, and managed. They have project management plans, firm start and completion milestones, prescribed performance requirements, and prescribed budgets. The DOE has divided projects into three distinct categories: MSAs, MPs, and other projects. 
Projects of significant importance to program objectives and that entail relatively large allocations of resources are designated by DOE as either MSAs or MPs depending primarily on the dollar value, $\$ 100$ million or more, or national importance. These types of projects require special management attention and must meet the additional control and reporting requirements of DOE Order 2250.1C (DOE 1988).

\subsubsection{Management Control System Requirement Application}

All types of work must comply with the following basic MCS core requirement actions:

- Identify a WBS structure that establishes work elements to the costaccount level and develop associated schedules.

- Prepare and issue a cost account authorization (CAA) for the authorization of work and preparation of cost account plans (CAP).

- Prepare CAPs using earned value techniques.

- Report and analyze variances within the thresholds required by the program and/or project.

- Prepare and control changes that impact recognized and established work scopes, budgets, and schedules.

Table 2-1 is a summary of MCS requirements as they apply to the various types of work.

\subsection{ORGANIZATION}

All work performed for DOE is organized using the WBS concept, which provides a clear definition and subdivision of the work assigned. Each operating program has its own separate product-oriented WBS that is used to manage program work. Likewise, each project organizes its work in a unique WBS. Projects designated as either an MSA or MP will have a project summary work breakdown structure (PSWBS) provided by DOE and will develop a contract work breakdown structure (CWBS) that continues the work breakdown from the lowest level of the PSWBS. A WBS dictionary which descriptively defines the WBS element is required for MSAs and MPs but is optional for others.

The WBS serves as the common denominator for the integration of planning, scheduling, budgeting, estimating, work authorization, assigning responsibility, measuring, and reporting cost accumulation. 


\section{Management Control System Flow Chart}

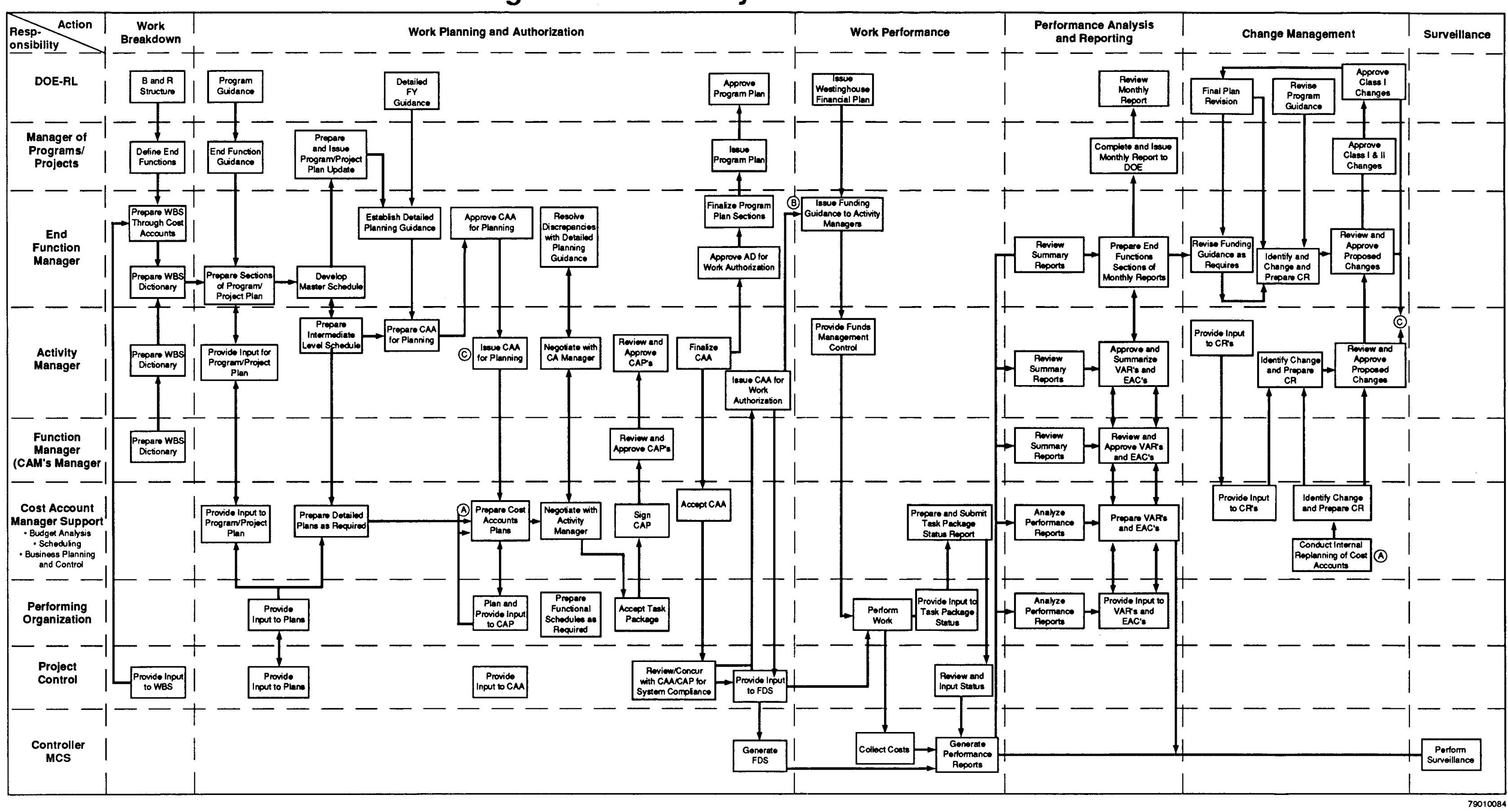


Blank Page 
Table 2-1. Management Control System Application. (sheet 1 of 2)

\begin{tabular}{|c|c|c|c|c|}
\hline Requi rements & MSA/MP* & $\begin{array}{l}\text { Other } \\
\text { projects }\end{array}$ & $\begin{array}{l}\text { Operating } \\
\text { programs }\end{array}$ & Procedure \\
\hline WBS & Required & Required & Required & HHC-CM-2-5, 1.1 \\
\hline WBS dictionary index & Required & Required & Required & WHC-CM-2-5, 1.1 \\
\hline WBS dictionary element definition & Required & Optional & Optional & WHC-CM-2-5, 1.1 \\
\hline Responsibility assigrment matrix & Required & Required & Required & WHC-CM-2-5, 1.1 \\
\hline Basel ine document & Required & Required & Required & WHC-CM-2-5, 1.3 \\
\hline Master schedule & Required & Required & Required & WHC-CM-2-5, 1.2 \\
\hline Intermediate schedules & Required & Required & Required & WHC-CM-2-5, 1.2 \\
\hline Cost account schedule & Required & Optional & Optional & WHC-CM-2-5, 1.2 \\
\hline Milestone control log & Required & Required & Required & $\begin{array}{l}\text { WHC-CM-2-5, } 1.2 \\
\text { Appendix } B\end{array}$ \\
\hline Milestone description sheets & Required & Required & Required & $\begin{array}{l}\text { WHC-CM-2-5, } 1.2 \\
\text { Appendix } 8\end{array}$ \\
\hline Cost account authorization & Required & Required & Required & WHC-CM-2-5, 2.1 \\
\hline CAPS in FDS & Required & Required & Required & WHC-CM-2-5, 2.2 \\
\hline Establish and Maintain a PMB & Required & Required & Required & WHC-CM-2-5, 2.3 \\
\hline Cost Account Manager's Notebook & Required & Optional & Optional & TBD \\
\hline Budget and Funds Control Log & Required & Required & Required & $\begin{array}{l}\text { WHC-CM-2-5, } 2.1 \\
\text { Appendix } 8\end{array}$ \\
\hline $\begin{array}{l}\text { Measurement of earned value at } \\
\text { task level }\end{array}$ & Required & Required & Required & $\begin{array}{l}\text { WHC-CM-2-5, } 2.2 \\
\text { Appendix } 8\end{array}$ \\
\hline Formatted cost performance reports & Required & None & None & WHC-CM-2-5, 3.1 \\
\hline Company performance reports & Required & Required & Required & HHC-CM-2-5, 3.1 \\
\hline Variance analysis reports & Required & Required & Required & WHC-CM-2-5, 3.1 \\
\hline Estimates at completion & Required & Required & Required & WHC-CM-2-5, 3.2 \\
\hline Trend analysis & Required & Optional & Optional & $\begin{array}{l}\text { WHC-CM-2-5, } 3.1 \\
\text { AppendiX } D\end{array}$ \\
\hline
\end{tabular}


WHC-EP-0388

Table 2-1. Management Control System Application. (sheet 2 of 2)

\begin{tabular}{|l|l|l|l|l|}
\hline \multicolumn{1}{|c|}{ Requirement } & MSA/MP* & $\begin{array}{c}\text { Other } \\
\text { projects }\end{array}$ & $\begin{array}{c}\text { Other } \\
\text { programs }\end{array}$ & Procedure \\
\hline Change control log & Required & Required & Required & $\begin{array}{l}\text { WHC-CM-2-5, } 4.1 \\
\text { Appendix C }\end{array}$ \\
\hline Change request & Required & Required & Required & $\begin{array}{l}\text { WHC-CM-2-5, } 4.1 \\
\text { Appendix B }\end{array}$ \\
\hline Change evaluation board & Required & Optional & Optional & $\begin{array}{l}\text { WHC-CM-2-5, } 4.1 \\
\text { Appendix B }\end{array}$ \\
\hline Change control board & Required & Optional & Optional & $\begin{array}{l}\text { WHC-CM-2-5, } 4.1 \\
\text { Appendix B }\end{array}$ \\
\hline
\end{tabular}

FDS = Financial data system

$T B D=$ To be determined

MSA = major system acquisition

$M P=$ major project

WBS = work breakdown structure

*Or other work designated by the U.S. Secretary of Energy to meet DOE Order 2250.1c requirements (DOE 1988). 
WHC-EP-0388

The WBS subdivides work to a manageable level, the cost account, where responsibility can be assigned, performance measured, and work controlled. This is the level where the work is integrated with the Westinghouse Hanford's functional organizational structure through the use of a responsibility assignment matrix.

\subsection{PLANNING AND BUDgeting}

Work is planned, scheduled, and budgeted following the framework established in the WBS and is authorized after thorough planning is completed. Work will be scheduled through a hierarchy of schedules that trace milestones from the master schedules to the point of completion. Progress of the work can be evaluated by tracking milestone status when compared with selected earned-value techniques.

The cost account level of the WBS serves as the integration point for work scope, schedule, and budget. All cost account work will be divided into tasks that will have time-phased budgets, earned-value measurement methods, and assigned performing organizations. This integration serves as the basis for the calculation of the performance measurement baseline (PMB). The PMB for any program and/or project is determined by adding the total budget of all authorized cost accounts to any undistributed budget.

\subsection{ACCOUNTING}

The Westinghouse Hanford Financial Data System (FDS) supports all Westinghouse Hanford accounting functions as they relate to cost and schedule contro1. Contract budgets are maintained and contract costs are accumulated by WBS reference. Cost and performance measurement data elements are accumulated and summarized from the bottom up as directly as possible, without allocations. Costs for materials are accumulated on a basis consistent with the budget to provide full accountability for all materials ordered, received, and used. The system separately identifies and controls indirect and overhead costs and applies them at the appropriate contract level.

\subsection{ANALYSIS AND REPORTING}

Analysis of data related to actual and planned performance takes place at the cost-account level of the WBS on a monthly basis. The results are available for further analysis at all levels of the WBS and Westinghouse Hanford functional organization structure. Analys is is only required of cost and schedule variances that exceed the minimum thresholds noted in Section 6.1 .2 or other thresholds established by individual programs and/or projects. For schedules, major and key milestones are analyzed monthly, statused, and significant variances reported. Variance reports identify the cause and impact of the variance and suggest actions to correct the variance. Estimates of the cost of completing remaining scheduled work are developed as a result of the analysis and reported as part of the variance analysis report. 


\subsection{CHANGE CONTROL}

Change control is designed to control and incorporate in a timely manner all contract changes directed by DOE and as well as those changes that result from Westinghouse Hanford replanning or formal reprogramming. Changes are classified as to impact and required approval level and are always traceable to the original agreed-on baselines. Contract and PMB changes are tracked from submission of the change request to full-change implementation. Retroactive changes to $\mathrm{planned}$ budgets, the value of work performed, and actual costs are prohibited with the exception of error correction and routine accounting adjustments.

\subsection{SURVEILLANCE}

The objective of surveillance is to ensure that the operating MCS continues to meet the guidelines established in this MCS Description. Surveillance entails a systematic approach to periodic, thorough reviews of MCS operation and maintenance. 


\subsection{ORGANIZATION}

This section describes the Westinghouse Hanford functional organization responsibilities as they relate to the integration of the WBS work elements down through the cost account level.

The Westinghouse Hanford management philosophy for the organization of work is based on a product-oriented WBS and related organizational structure that reflect the influence of the multiple and varied programs and/or projects for which Westinghouse Hanford is responsible.

To ensure cost-effective operation and to achieve performance objectives without jeopardizing safety and quality, Westinghouse Hanford has designed an organizational structure that permits flexibility in shifting work force assignments while maintaining organizational stability. This structure relies on the cross-support or functional organization philosophy.

The WBS is subdivided into clearly defined units of work that comply with the DOE-RL- and Westinghouse Hanford-identified performance reporting levels. The clearly defined units of work are then integrated at the cost-account level in a responsibility assignment matrix with the cross-support or functional organization structure to align the proper technical disciplines with the appropriate elements of responsibility. This is the point where work responsibility assignments are formalized. The WBS is the integrating tool used as a common reference point for planning, budgeting, estimating, work authorization, and cost accumulation. A WBS dictionary, index, or element definition will be prepared to assist in understanding the work scope to be performed.

Although the final responsibility for the successful work planning, monitoring, and controlling rests with the program and/or project manager, performance can be measured at each level of both the WBS and the organization. The program and/or project manager will delegate responsibility by WBS element to cross-support organizations depending on the availability of appropriate resources as depicted in Figure 3-1.

Four WBS element responsibility levels are supported by the Westinghouse Hanford FDS: (1) program and/or project, (2) end function, (3) activity, and (4) cost account. The number of actual WBS levels will vary depending on the complexity of the work scope, but they should be extended to the level required to encompass all manageable units of work.

The following sections describe typical project and program roles of the key organizations and WBS element levels responsible for planning, monitoring, and controlling work at Westinghouse Hanford. Where a WBS element level is not used, the described responsibilities remain at the next higher WBS element level. 
Figure 3-1. Contract Work Breakdown Structure and Responsibility Assignment Matrix.

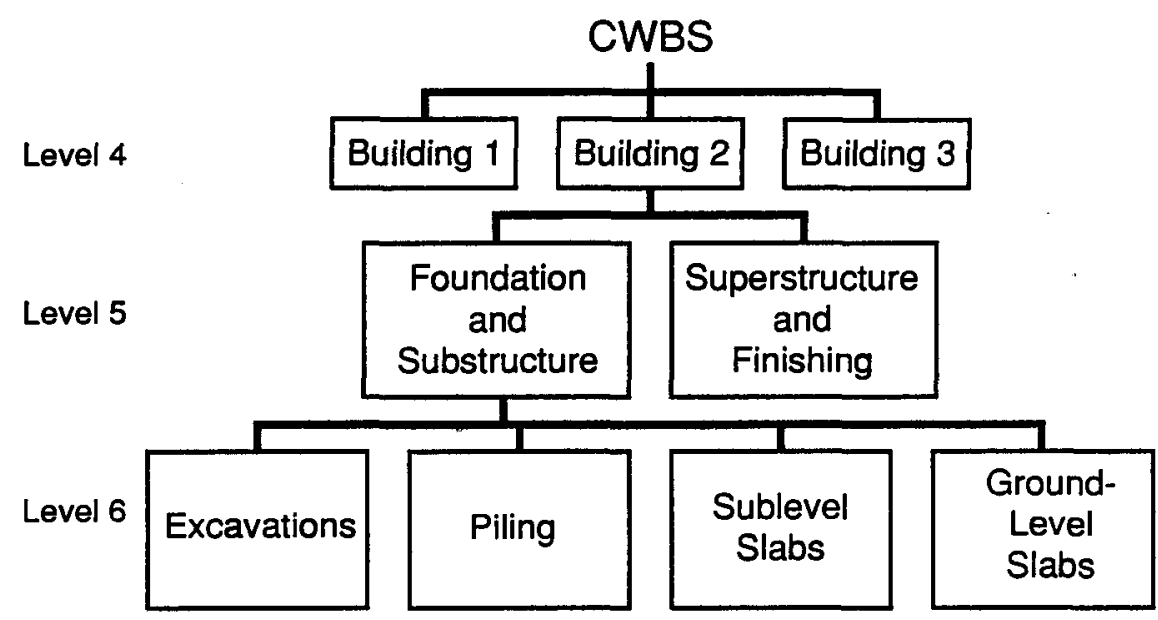

Integrating the "What" with the "Who"

Work Breakdown Structure

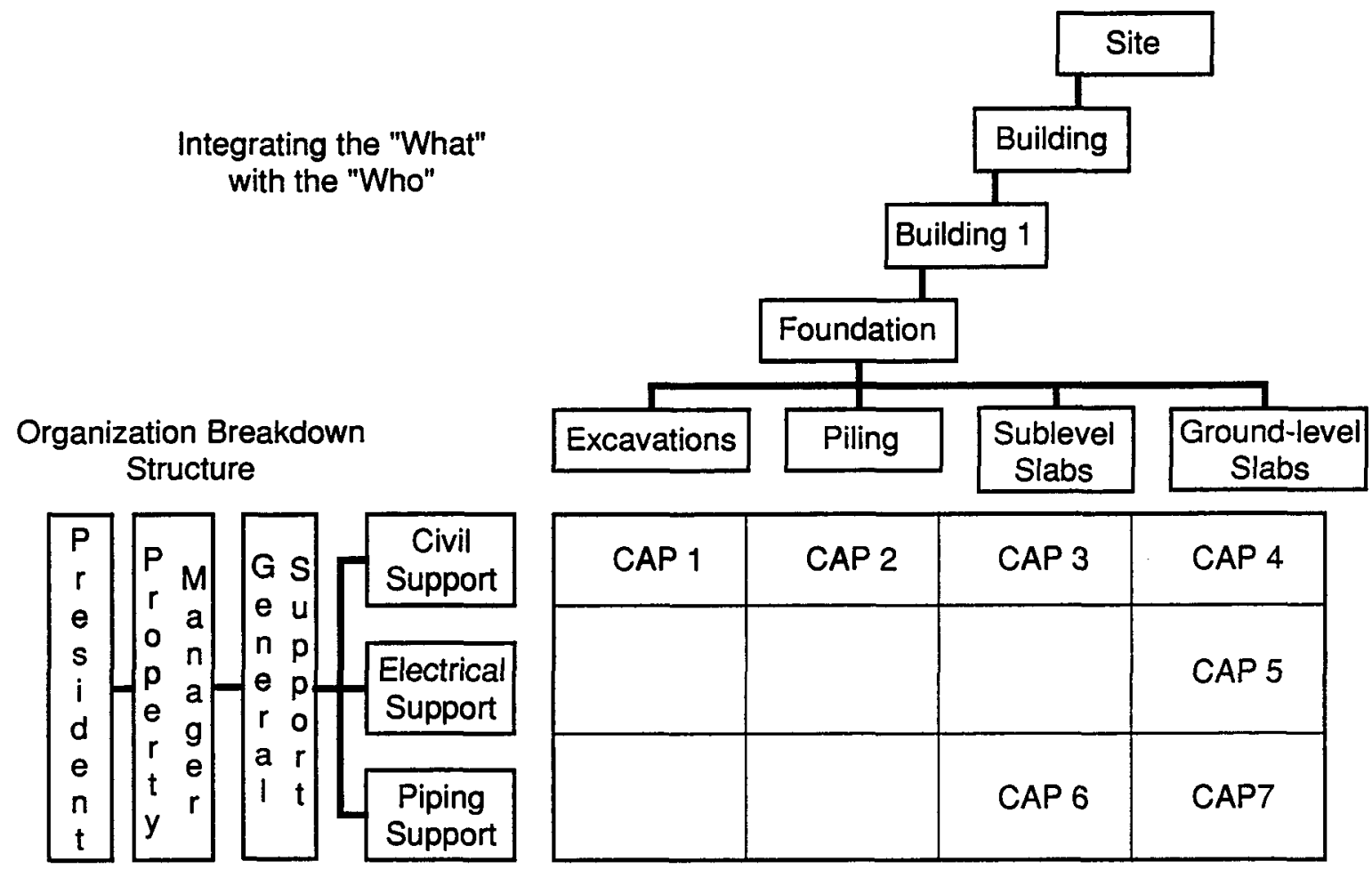

R9010052.4 
WHC-EP-0388

\subsection{PROGRAM AND/OR PROJECT MANAGER}

The program and/or project manager is responsible for establishing general program and/or project guidance based on direction from the DOE-RL or other customers. Their responsibility also includes the establishment of a single WBS that encompasses all work for their specific program and/or project and provides planning direction to the end-function WBS element level. Overall responsibility within the assigned program and/or project area is accomplished through the following actions:

- Distribute funds in support of authorized work.

- Direct the preparation and execution of baseline documents.

- Report progress to DOE-RL or other customers.

- Approve changes, as required.

\subsection{PROGRAM ADMINISTRATION OR PROJECT CONTROL}

Program administration and project control are the program- and projectspecific organizations responsible for the documentation of budget and reporting requirements. The program administration or project control organization provides support to those responsible for all levels of the WBS structure through the following actions:

- Assist those responsible for WBS work elements with cost and schedule planning and control.

- Ensure that the CAA and CAP comply with MCS requirements.

- Compile monthiy and quarterly performance reports.

- Exercise baseline data control by the maintenance of control logs.

- Assist in the resource loading of cost accounts.

- Ensure that cost accounts with significant variances are thoroughly analyzed and variance analysis reports (VAR), which identify the scope of work, are prepared.

- Enter task packages into the FDS.

- Maintain and report performance measurement information for the cost accounts to program and/or project managers or their designee.

\subsection{END FUNCTION WORK BREAKDOWN STRUCTURE LEVEL}

The End Function Level Manager, where assigned, is responsible for the total work definition, work planning, work authorization, work performance, 
performance analysis, performance reporting, and change control for the assigned work. The Manager accomplishes these responsibilities through the following actions:

- Prepare baseline documents including the development of schedules.

- Authorize cost account preparation and detailed planning.

- Prepare end function monthly reports.

- Initiate change documents as required.

\subsection{ACTIVITY WORK BREAKDOWN STRUCTURE LEVEL}

The activity level manager, where assigned, is responsible for the following actions:

- Prepare and issue CAAs that define work scope, schedules, and budgets for cost accounts.

- Negotiate budget, schedule, and major milestones with the cost account level.

- Approve CAPs.

- Prepare and approve change documents as required.

\subsection{COST ACCOUNT WORK BREAKDOWN STRUCTURE LEVEL}

The cost account level manager is responsible for the detailed planning and performance, including the technical quality, of work within the assigned cost accounts. This is accomplished through the following actions:

- Develop the CAP in agreement with the scope, schedule, and budget provided in the CAA.

- Define, plan, schedule, and negotiate supporting work from other organizations as required.

- Maintain proper change control of assigned cost accounts.

- Evaluate performance against the CAPs, summarizing variance analyses, and evaluating corrective action plans at the activity level.

- Prepare variance analysis reports for variances that exceed the approved thresholds. 
- Develop estimate-at-completion (EAC) forecasts.

- Ensure proper close-out of CAP.

The cost account is the element of work around which the MCS is developed. The cost arcount is divided into work packages, and then task packages, to help the organization assign the work to be accomplished.

NOTE: The cost account level manager must maintain signature authority commensurate with the assigned responsibilities.

\subsection{PERFORMING ORGANIZATIONS}

Tasks identified in the CAP are assigned to performing organizations, which have the responsibility for the performance of the work within that given task package. The performing organization should be within the responsible WBS element except when matrixed support is required from a supporting organization. When different from the organization responsible for the cost account WBS element level, the performing organization is responsible for helping with detailed planning, performing the assigned work, and assisting in the analysis of variances against the CAP. This is accomplished through the following actions:

- Integrate assigned task packages.

- Provide analysis of performance, as required.

\subsection{MANAGEMENT CONTROL SYSTEM ORGANIZATION}

The MCS organization is responsible for the development and maintenance of the MCS as outlined in this system description and further delineated in the MCS procedures manual (WHC 1990). These responsibilities include the following actions:

- Provide training support, recommendations, and guidance to Westinghouse Hanford personnel, where appropriate, in matters relating to the MCS.

- Review program and/or project cost account planning and procedures to ensure proper compliance with the MCS.

- In conjunction with FDS, ensure the maintenance of data files that generate automated performance reports and resulting changes through formal change management.

- Conduct periodic system surveillance, identify discrepancies, notify affected organizations, and support corrective actions. 
The roles and responsibilities of the MCS organization may change depending on the changing contractual role of Westinghouse Hanford as an integrating contractor, associate contractor, or participating contractor. Regardless of these or other changes, the MCS organization will ensure continuity and consistency of the performance measurement methods used within Westinghouse Hanford. 


\subsection{PLANNING AND BUDGETING}

The work planning and authorization process is an expansion of the work organization process and includes further refinement of a scope of work schedule and budget and communicating authority for work performance to the responsible organizations. The integration of work, schedule, and budget, including the appropriate selection of the most appropriate performance measurement method, is of significant importance to the process.

A well-conceived and appropriately detailed plan for the work, prepared to the cost account level, is critical to the success of the MCS. The work is planned to completion with more-detailed planning for the near term and progressively less detail for the outyears. The planning for the Westinghouse Hanford MCS begins with the preparation of planning documents, a project management plan or program plan as appropriate, that describes the framework and relationships within which the work will be accomplished. These planning documents include a master schedule and the WBS dictionary for the respective scope of work. Both the schedules and the WBS flow down to the level where responsibility is assigned and work is performed. At this level work is defined in a forma'l CAA that specifies the boundaries (scope, schedule, and budget) for each CAP and is used by the cost account manager (CAM) for planning the work details. The CAAs and CAPs are reviewed and formally approved by management. The CAPs become the lowest level baseline plan and reflect the integration of budgets and schedules for planned work. With final approval of the CAAs and CAPs, charge codes are validated in the FDS to authorize charging of performed work. The major steps within the work planning and authorization process are shown in Figure 4-1.

\subsection{ESTIMATING}

The WBS constitutes the framework for the estimate and for subsequent cost collection and reporting. Using the WBS provides a systematic approach to cost estimating that ensures relevant costs are not omitted. In addition, it serves as a vehicle to constantly refine cost estimates as the program and/or project progresses.

In defining the estimating task, the estimator should determine which items of the program and/or project WBS apply to the estimating job at hand and the level of aggregation to be used for each item selected.

The specific assignment of responsibility for estimating and the methodology employed by Westinghouse Hanford for coordination with the architectural engineer (AE) and project engineer will be determined by DOE-RL and conveyed to Westinghouse Hanford. Additional implementation instructions may be found in DOE-RL Orders 4700.1 and 5700.3 (DOE-RL 1989, 1985). 


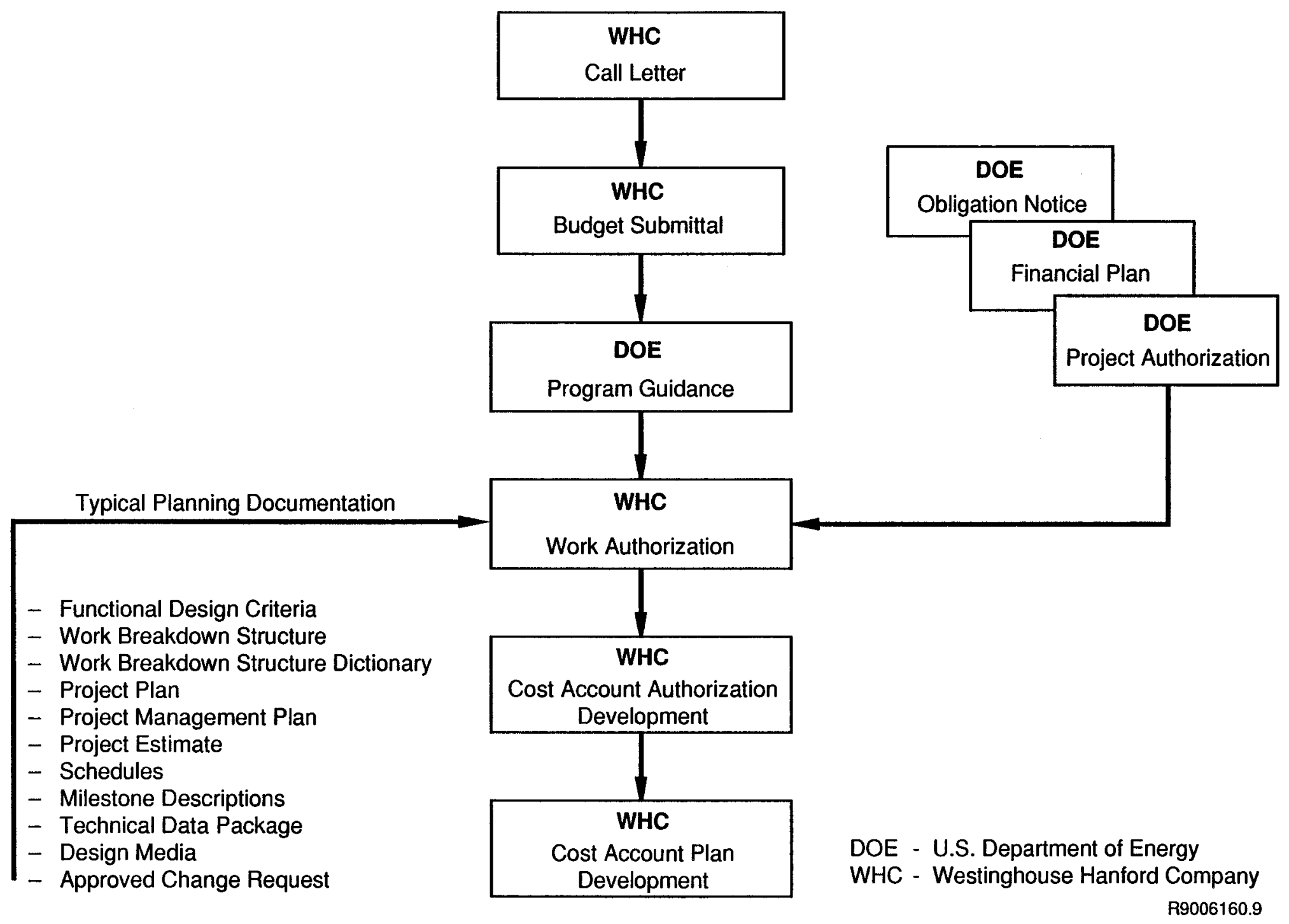


WHC-EP-0388

\subsection{RELATIONSHIP OF PLANNING ACTIVITIES WITH THE ANNUAL PLANNING AND BUDGETING CYCLE}

Each fiscal year budget is the culmination of several years of planning effort by both Westinghouse Hanford and the DOE-RL. This process of developing long-range forecasts is called the annual planning and budgeting cycle (Figure 4-2). The process uses multiyear plans, continually updated to reflect current conditions and guide the establishment of near-term goals and objectives. (Reference procedure WHC-CM-2-5, 3.7.)

Westinghouse Hanford begins detailed consideration of funding requirements several years in advance, when detailed forecasts of work that define resource estimates and funding requirements are made. Each year, the detailed forecasts are revised, and plans are expanded to include more current and specific information. These refinements reflect the latest DOE-RL guidance.

The program and/or project planning documents and the updated DOE-RL guidance constitute the principal assumptions and direction required to complete DOE-RL assigned work.

The intention of the planning and budgeting cycle is to provide accurate cost, schedule, and work-scope integration so that appropriate program decisions can be made and funds can be allocated in a timely manner. In addition, this cycle establishes a firm baseline for measurement of performance. Thus, even though the execution of the steps shown in Figure 4-2 is a separate concern from day-to-day management of Westinghouse Hanford activity, it supports the general management activities of the MCS. As the annual planning and budgeting cycle impacts the plans within the MCS, updates are made to the project or program planning documents and other project baseline documentation, including CAPs, through formal change control.

\subsection{BASELINES}

Baselines are identified and established at the program and/or project level and further detailed through the WBS down to the level of the CAAs and the CAPs. Formal disciplined change control of the elements and documents that constitute the baselines are a Westinghouse Hanford mandatory management requirement. The various baselines are described below. (Reference procedure WHC-CM-2-5, 2.3.)

- Budget Baseline--This baseline, from which performance is measured, is initially developed from the official cost estimate for the total scope of work. It is structured by the WBS, tied to the schedules, and centered on the cost account. The PMB is the sum of the timephased, cost-account budgets and the budget for work that has not been identified with sufficient clarity to distribute and plan in a cost account. This identified but unplanned work budget is termed 


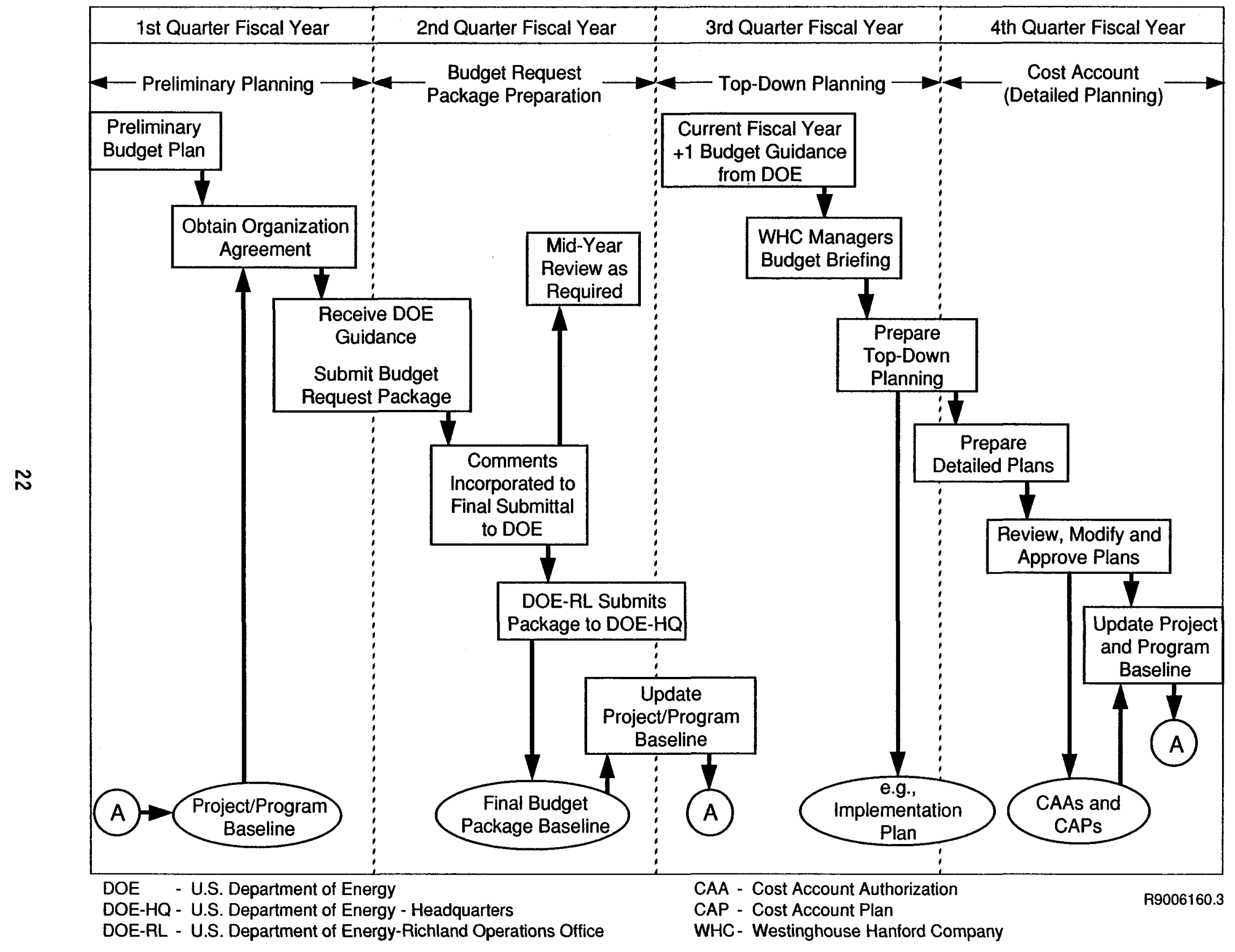

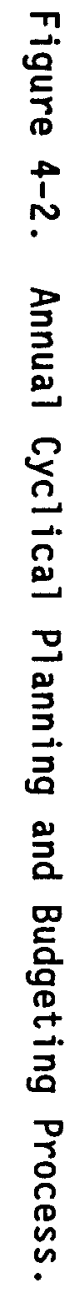


WHC-EP-0388

undistributed budget (UB). The PMB plus the management reserve constitute the budget at completion (BAC), which is also termed the contract budget base (CBB). Figure 4-3 illustrates these relationships.

- Schedule Baseline--This baseline consists of formally approved schedules including all major and key milestones which are defined in the milestone log described in Section 4.6.

- Technical Baseline--This baseline includes the criteria, functions, requirements, and scope to produce a specified product. This data is generally identified in design drawings, specifications, and process flow sheets. The top-level technical baseline document for projects is the functional design criteria (FDC), which is controlled by DOE-RL and guides the design-development and construction phases of the project.

- Scope-of-Work Baseline--This baseline is established in the WBS dictionary and program planning documents and is further detailed in the CAAs. This baseline is also included in other program and/or project baseline documentation, where applicable.

- Funds Baseline--This baseline is the upper limit for either budget authority or budget outlay as authorized on the most current authorization (DOE project authorization or obligation notice as appropriate).

\subsection{PROJECT MANAGEMENT PLAN}

All projects are required to have a project management plan (PMP) in accordance with DOE Order 4700.1 (DOE-RL 1989). The PMP contains an overview of the project, key project objectives and performance criteria, an outline of management systems to be used, a description of the project organization, and a statement regarding the responsibilities of each project participant. The PMP includes the PSWBS, the PSWBS dictionary, and the initial master budget and schedule and milestone baseline logs. It also identifies project specific directives (e.g., reporting thresholds). Changes to the PMP are formally processed by the project change control system. (Reference procedure WHC-CM-2-5, 4.1.)

\subsection{PROJECT BUDGET BASELINE ELEMENTS}

\subsubsection{Contract Budget Base}

The total CBB includes the sum of the PMB, plus the undistributed budget, plus management reserve. In the absence of a specific negotiated contract cost, the CBB is the total budget formally recognized by both the DOE and Westinghouse Hanford as the value to be used for contract performance measurement purposes. 
Figure 4-3. Budget Baseline Element Relationships.

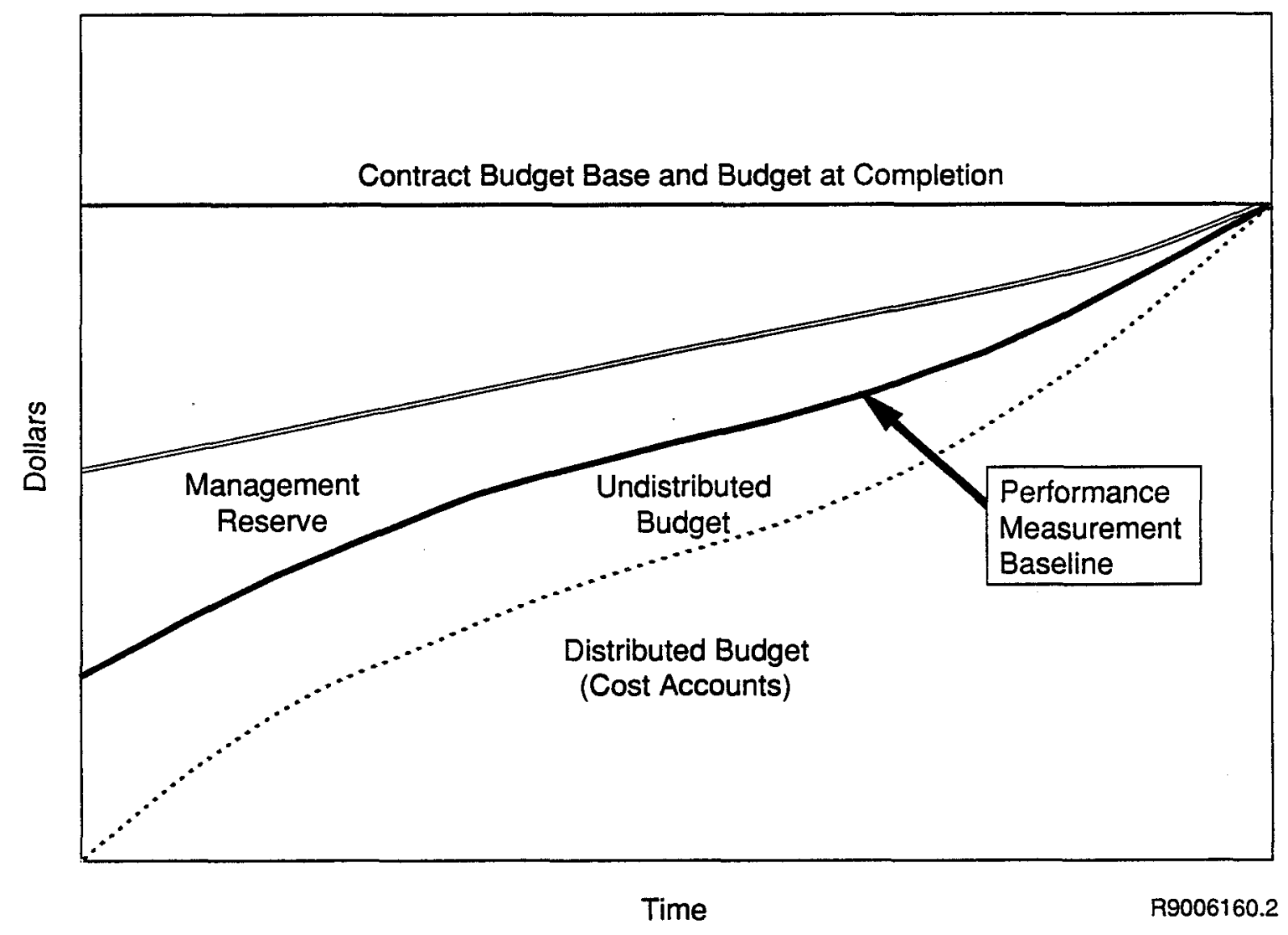




\section{WHC-EP-0388}

\subsubsection{Performance Measurement Baseline}

The PMB includes all time-phased CAP budgets plus remaining undistributed budget. The PMB provides the ability to identify variances to schedule and budget and forecast estimates of the cost to complete work.

\subsubsection{Management Reserve}

Management reserve (MR) is that portion of the CBB withheld by Westinghouse Hanford as applicable for management control purposes rather than for budgeting specific tasks. The Westinghouse Hanford MR is maintained separately from the PMB (to keep from distorting the PMB) and is used to budget in-scope work not initially identified or planned. When MR is applied to specific task planning, the MR is reduced and the PMB is increased accordingly and DOE-RL is notified via the change control process as applicable. Management reserve should not be confused with funding contingencies, which are established and controlled by DOE-RL.

Construction projects include both capital and expense funds and require accurate reconciliation to their application. The capital estimate of a project includes a percentage for "known unknowns" and is termed contingency. Thus, the administration of change control for contingency is similar to MR, with a clear and distinct accounting made to distinguish MR from contingency.

The MR portion can also be established as part of a program budget at the program or end-function level. Its use must be controlled and reported as described above.

\subsubsection{Undistributed Budget}

Undistributed budget represents established budget for identified work that, because of time constraints or insufficient technical information, has not been formally assigned to a WBS element. The undistributed budget is controlled by the program and/or project manager until such time that a task can be defined. The budget designated as undistributed budget and the work associated with it is assigned to the appropriate cost accounts as quickly as the unknown aspects can be determined. When undistributed budget is assigned to a cost account it requires formal change control to ensure the integrity of the performance measurement baseline.

\subsection{SCHEDULE HIERARCHY}

\subsubsection{Schedule Hierarchy Description}

Schedules for all work to be done are developed in a family tree hierarchy that allows traceability from the top level down to the bottom level of the WBS. The critical path(s) for the program and/or project is defined and schedule float identified. Resources are allocated and distributed to 
scheduled activities to provide integration and congruence for baseline management and control. Control milestones are selected as objective measurable indicators of work performed. Major milestones are those milestones selected by DOE to monitor and control the project. They represent significant objectives, constraints, or relationships that have been determined to be critical to the success of the project. These milestones are usually provided by DOE-RL to Westinghouse Hanford by letter, fiscal year operation directives, award fee goals, or other type of formal guidance. Key milestones represent objectives that Westinghouse Hanford has determined to be important additional control points. (Reference procedure WHC-CM-2-5, 1.2.)

Major (i.e., DOE) and selected key (i.e., Westinghouse Hanford) milestones are entered in a milestone control $10 \mathrm{~g}$ and are documented on the master schedule. Intermediate schedules, which facilitate the tracing of schedule constraints, decision points, and interfaces, are also prepared to manage the project. The cost account schedules provide the lowest level of detail of the schedule hierarchy. Section 4.7 identifies examples of source documentation used in the preparation of schedules. Schedule status is updated monthly, progress is summarized, and information is provided in the Westinghouse Hanford program and/or project manager's monthly report, which also includes a forecast of completion dates.

\subsubsection{Schedule Levels}

The schedule hierarchy (see Figure 4-4) is summarized below and is applied as appropriate.

1. Integrated Milestone Schedule (Level 0 )--The Integrated Milestone Schedule is developed for the DOE by the Westinghouse Hanford to visualize major milestones that support assigned Westinghouse Hanford objectives and mission(s). Lower-level schedule commitments will be traceable to the designated major milestone. This schedule becomes a basis for outyear planning. These objectives will be reflected in each program and/or project plan, in other long-range planning documents, and on the activity data sheet. This schedule will depict the life-span of the mission(s) and related program and/or project. The Level 0 schedule is approved by the DOE-RL.

2. Master Summary Schedule (Level I)--The master schedule is the top level schedule for programs and/or projects. It contains all major and selected key milestones. It portrays the scope of work at the program and/or project level. Each bar represents a summary of the work at the WBS end function level. It extends for the life of the program and/or project. For projects the Level I schedule is approved by the project manager and appropriate reporting management. For programs the Level I schedule is approved by the appropriate responsible manager and reporting management.

3. Master Operating Schedule (Level II)--The master operating schedule includes all CAA milestones. Expense-funded and capital-funded work may be included on a single schedule or specific WBS elements may 
Figure 4-4. Schedule Hierarchy.

\begin{tabular}{cc|} 
Level 0 & $\begin{array}{c}\text { Projects and Program } \\
\text { Integrated } \\
\text { Milestone } \\
\text { Schedule }\end{array}$ \\
Level I & $\begin{array}{c}\text { Master } \\
\text { Schedule }\end{array}$ \\
Level II & $\begin{array}{c}\text { Master } \\
\text { Operating } \\
\text { Schedule }\end{array}$ \\
Level III & $\begin{array}{c}\text { Cost } \\
\text { Account } \\
\text { Schedule }\end{array}$ \\
\hline & \\
Level IV & $\begin{array}{c}\text { Working } \\
\text { Schedule }\end{array}$ \\
\hline
\end{tabular}

R9010052.1 
require separate schedules depending on the work complexity. Each bar represents a summary of the work at the WBS cost account level. For projects the Level II schedule is approved by the project manager and reporting management as appropriate. For programs the Level II schedule is approved by the appropriate responsible manager and reporting management.

4. Cost Account Schedule (Level III)--The cost account schedule includes all cost account milestones. It depicts work package activities in logical sequence and shows interrelationships and dependencies within and between cost accounts. It shows when and how the work package activities culminate to meet major and key milestones. The cost account schedule is approved by the activity manager and CAM.

5. Working Schedule (Level IV)--The working schedule depicts the entire work scope for the program and/or project and includes CAP detail including work packages and task packages over a period of 18 months showing major and key milestones and other cost account interfaces. It provides a firm basis for calculating performance measurement. This is the lowest level program schedule. The Level IV schedule is approved by the CAM.

All major and key milestones, selected to enhance visibility and provide control, are entered on a milestone control log. (Figure 4-5 is a suggested form.) The milestone control $\mathrm{log}$ is used to record change to evaluations including listing controlled milestones with the original, revised, and actual completion dates of each. In addition, all milestones are formally defined in milestone description sheets.

\subsection{COST ACCOUNT AUTHORIZATION}

The CAA identifies the required scope of work, budget, deliverables, schedule constraints, CAM, and responsible organization for a CAP. The following approved and controlled documentation may support the development of the CAA: FDC, technical data package, project plan, PMP design media, approved change request, WBS estimate, DOE guidance directive, statement of work, schedule baseline, WBS dictionary, or milestone log. (Reference procedure WHC-CM-2-5, 2.1.)

The CAA has three purposes: (1) document the planning process; (2) define the scope, objectives, deliverables, and budget funding for the CAM; and (3) authorize the start of work after planning is approved. Project-approved documentation is used to develop work scope, schedule, resource estimate, and budget for the CAA. The CAA is prepared by the activity manager with input from the CAMs and the functional performing organization, if known. The CAA is, in essence, a contract between the CAM and the program and/or project. The scope, schedule, and budget must be defined sufficiently to establish the cost account bases from which changes can be controlled. 


\section{Westinghouse Hanford Company}

(1) I I TLE

Program Milestone Control Log

\section{Milestone Control Log}

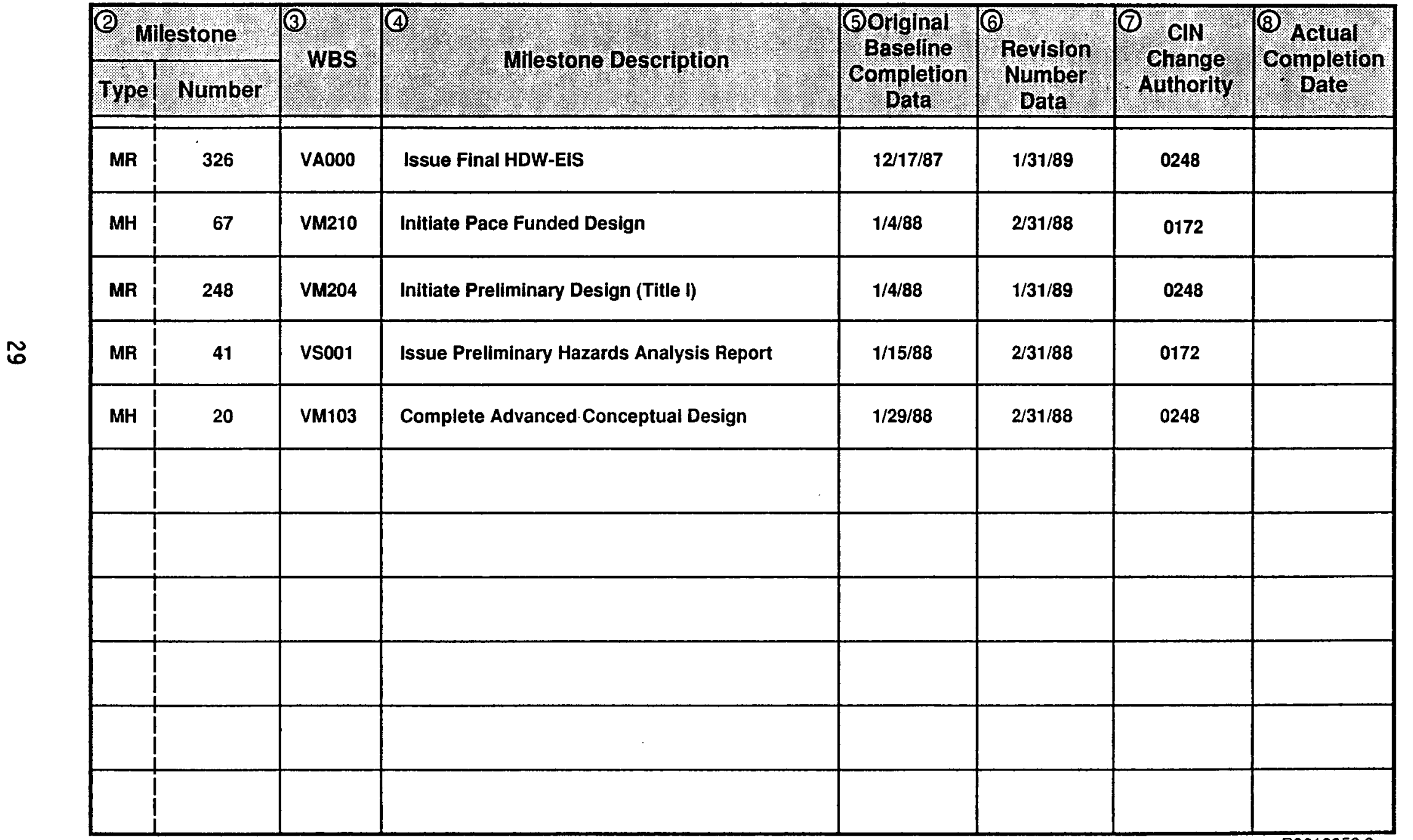


The CAA is prepared for each cost account in advance of the start of the planned work. (Figure 4-6 is an example of a CAA.) The program administration or project control organization assists in the preparation of the CAA. The cost account number on the CAA is tied to the applicable WBS element. The scope, schedule, and budget must be consistent with the program and/or project planning documents, schedules, and current DOE-RL budget guidance. The program and/or project manager signs the CAA giving the CAM authority and guidance to plan all the approved cost account work. Thus, the CAA is provided to the CAM to authorize preparation of the CAP.

\subsection{COST ACCOUNT PLAN}

The CAP is used by the CAM to plan the details of the assigned work based on the guidance provided in the CAA. Cost accounts are subdivided into elements of work called work packages and planning packages. Work packages are further subdivided into more manageable pieces of work called task packages. Task packages are near-term tasks that have a well-defined scope, schedule, and budget. Planning packages are future tasks that can only be planned in general terms. The detailed allocation of budget required to do the work is documented on the CAP within the FDS, which provides cost account identification information (e.g., WBS number), work scope, earned value method, time-phased budgeted cost of work scheduled (BCWS), schedule, and milestones for each task package. Time-phased budgets are established by the CAM for each task package. The measurement of these resources are the values to be earned for accomplishment of the work, and their summation is called the BCWS. The CAP identifies the associated resources as cost elements, such as labor, material, and overhead, for all work budgeted. Figure 4-7 shows a CAP work sheet that is suggested for use for initial CAP planning. Figure 4-8 shows a page from a typical CAP as it exists in the FDS. (Reference procedure WHC-CM-2-5, 2.2.)

Work packages are smaller manageable units of work defined over the length of the cost account. Work packages comprise the related tasks to be performed. Each work package is clearly distinguishable from other work packages.

Task packages are limited to a single distinct element of work with the time span required to accomplish that work. An exception to this concept is level of effort (LOE) activity (Section 4.9). Task packages should be planned to be performed by a single organization. The size of task packages should reflect the size and complexity of the job and avoid micromanagement and proliferation of documentation. Each task package also has a stated start and completion date and a single earned value method. Task packages are planned by the applicable cost elements.

Planning packages are a necessity for projects that cover several fiscal years. A planning package is work that will be done far enough in the future that the details of how the work will be accomplished are not available. 


\begin{tabular}{|c|c|c|c|c|c|c|c|c|c|}
\hline \multirow[t]{2}{*}{1 Cost Account } & \multirow{2}{*}{$\begin{array}{l}\text { CAA Title } \\
\text { Activity Title }\end{array}$} & \multirow{2}{*}{\multicolumn{4}{|c|}{$\begin{array}{l}\text { COST ACCOUNT AUTHORIZATION } \\
\text { Program/Project }\end{array}$}} & \multirow{2}{*}{\multicolumn{2}{|c|}{$\frac{\text { Activity Mgr. }}{\text { Orıginal }}$}} & \multicolumn{2}{|l|}{ Date } \\
\hline & & & & & & & & & \\
\hline \multicolumn{2}{|c|}{ Resp. Org. Title/Code } & $\begin{array}{c}\text { Original Budget } \\
\text { (KS) }\end{array}$ & $\begin{array}{l}\text { Budget Prior } \\
\text { Revision }\end{array}$ & $\begin{array}{l}\text { Changes This } \\
\text { Revision }\end{array}$ & $\begin{array}{l}\text { Current Total } \\
\text { Budget }\end{array}$ & Start & Complete & Start & Complete \\
\hline \multicolumn{2}{|c|}{ Cost Acct. Mgr./Phone } & & & & & & & & \\
\hline
\end{tabular}

Funding Source: $\square$ Operating Expense $\square$ Line ttem $\mathrm{FY}$

$\square$ GPP EY

$\square$ CWO EY

D CENRTC FY

B8R Code

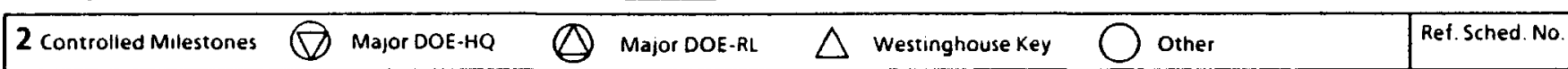

Iype

Description

Date

3 Description / instructions (scope, objectives, approach, constraints, further milestone definition) (capital justification)

$\omega$

\begin{tabular}{|c|c|c|c|c|c|c|c|c|}
\hline & & & & & & Total CAP 5000 & G\&ANCSP $\$ 000$ & Total CAA $\$ 000$ \\
\hline 4 & Distribution & \multicolumn{7}{|c|}{ Approvals } \\
\hline \multirow{5}{*}{$\begin{array}{l}\text { (1) } \\
\text { (2) } \\
\text { (4) }\end{array}$} & \multirow{5}{*}{$\begin{array}{l}\text { Program Administration' } \\
\text { ProjectControl } \\
\text { End Function Manager } \\
\text { Activity Manager } \\
\text { Cost Acct Manager }\end{array}$} & Title & Authority to Initiate Planning & Date & Title & \multicolumn{2}{|c|}{$\begin{array}{l}\text { Cost Account / Work Author } \\
\text { Aproval }\end{array}$} & Date \\
\hline & & Activity Manager & & & Program Administration & & & \\
\hline & & End Function Manager & & & Cost Account Manager & & & \\
\hline & & Cost Account Manager & & & Activity Manager & & & \\
\hline & & Program Administration & & & End Function Manager & & & \\
\hline
\end{tabular}

Page __ of _ 


\section{COST ACCOUNT PLAN WORK SHEET}

HESTINGHOUSE HANFORD COMPANY

SOLUTION TO CONTROL TECHMIQUES - PROBLEM \#1

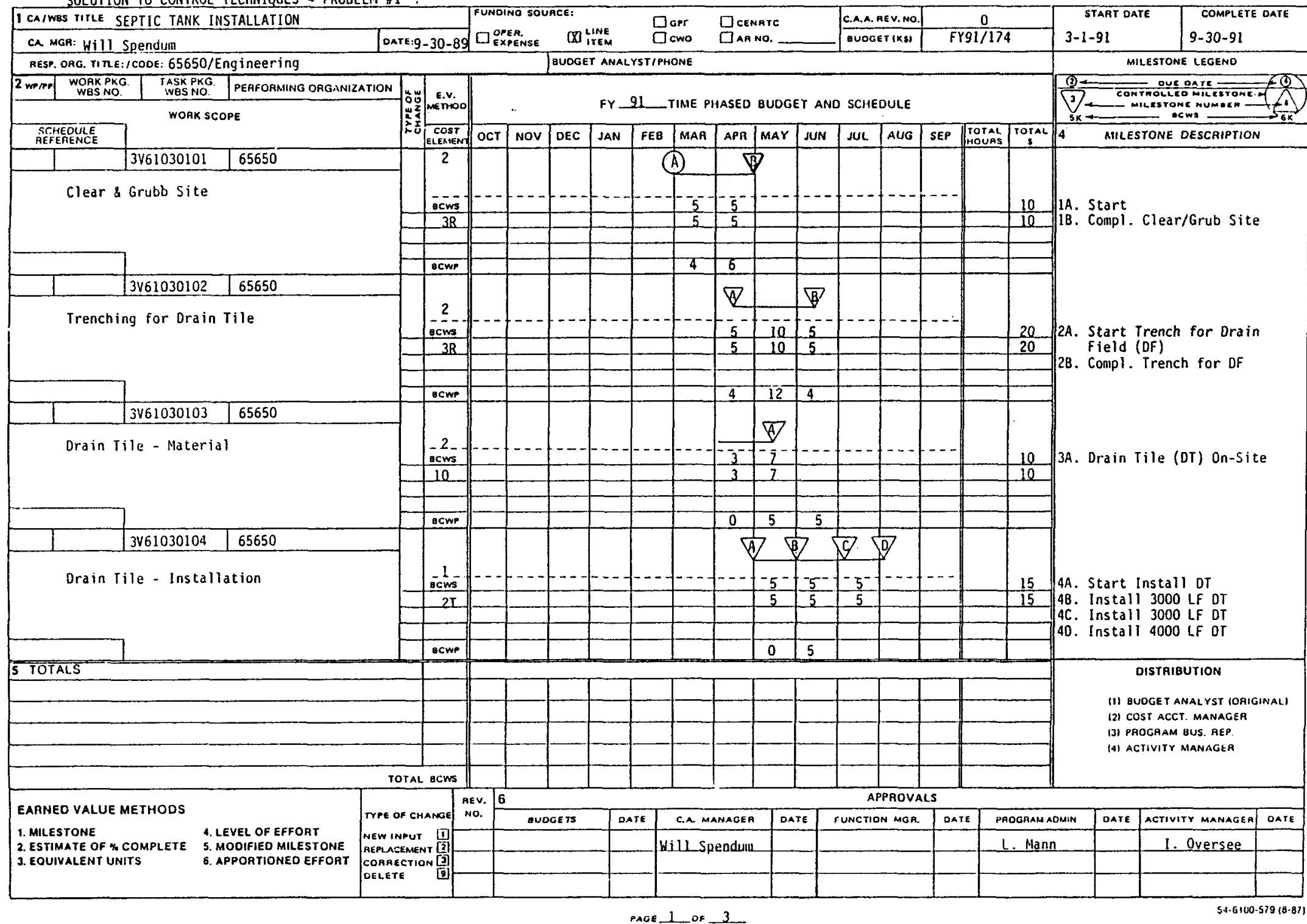


Figure 4-8. Example of cost Account Plan.

F[IS-ES $201-6$
Firarialal I:ata Systerí

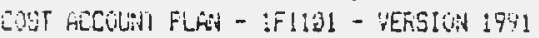

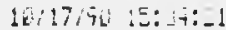
Fäte: $\quad$ :

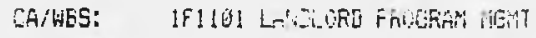

CA Manager: SChillti, En

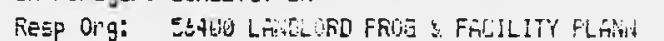

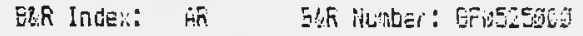

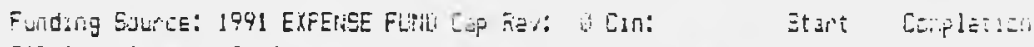

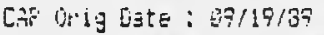

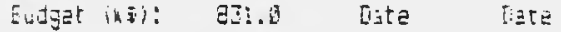

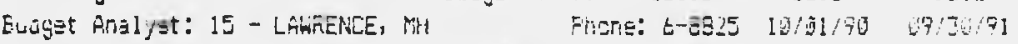
E星 Title :

\begin{tabular}{|c|c|c|c|}
\hline WGEKK PÄCKÁGE: & 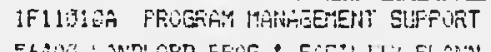 & Scupe of kark: & Sevision Nu: \\
\hline Resp of & 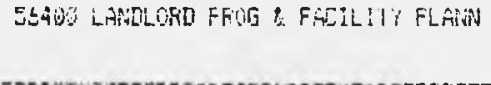 & 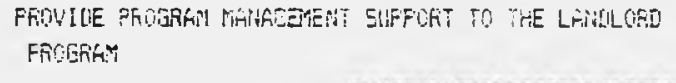 & Date: $18 / 24 / 7$ \\
\hline
\end{tabular}

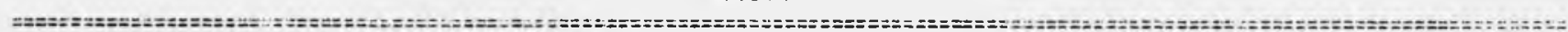

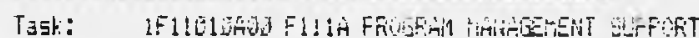

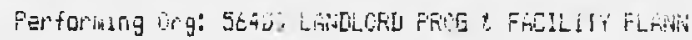
EV itethod: + LEVLL IF EFFORT PETHE Parent HES:

îppraved Ey:

Cost Elemente:

Fiscal Yesi': 1991

Etaff $i, z^{2}$

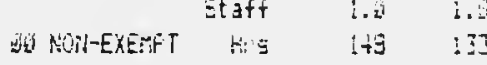

B1 ĔLISFT

Stist

ris

$$
\text { i }
$$

i

3] EXERFT GNERTI hir

Stati

$5 \quad 40$

4.5
719

24.7
- IEE F F

Ecope of biork:

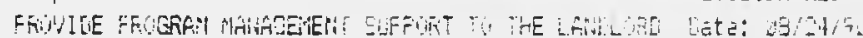
FRishint

Con isisi:

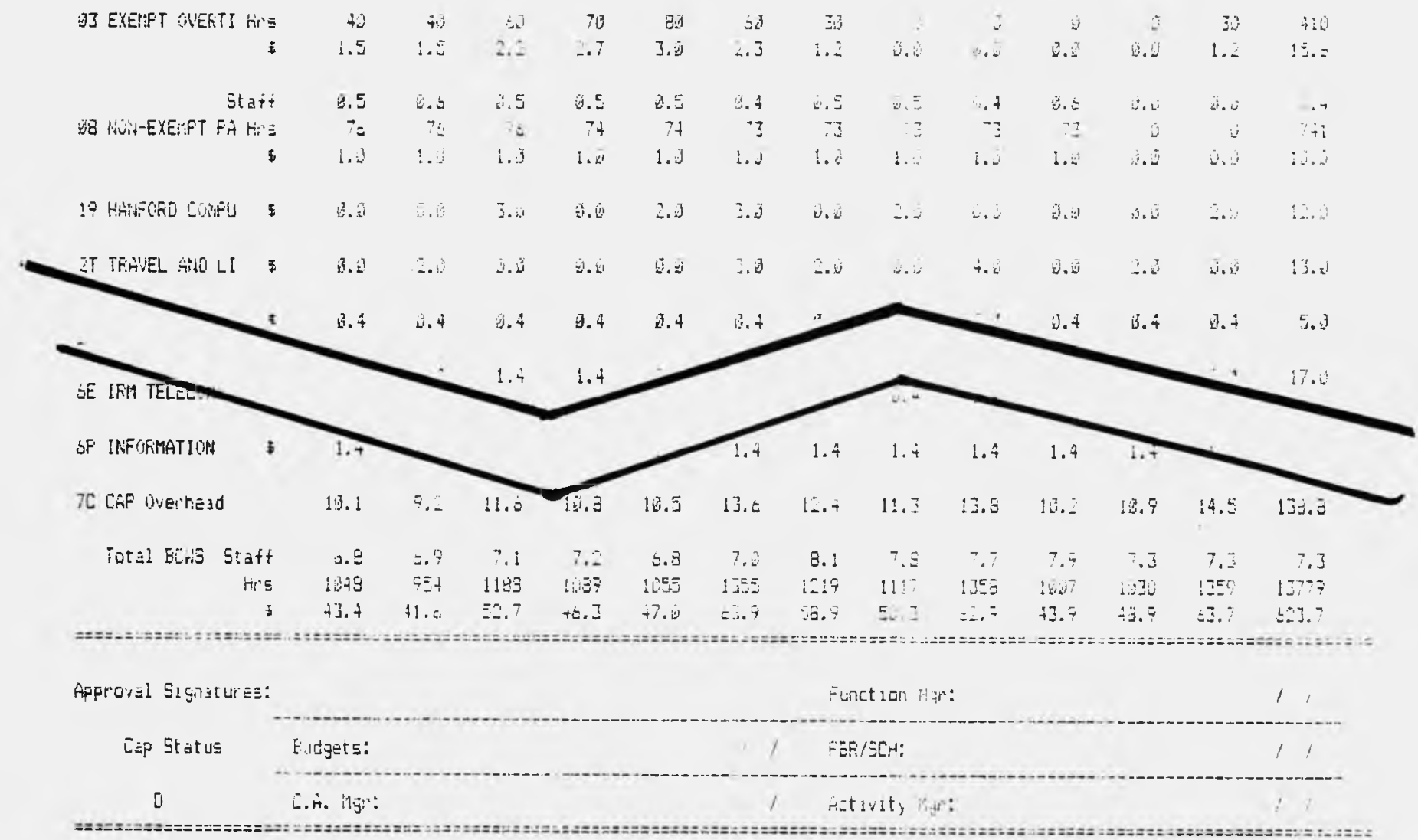


Normally, a planning package is appropriate when the start of the work is at least 6 months away and the work has not yet been defined. Planning packages - do not require selection of earned value methods or the identification of all the organizations and cost elements that will eventually be assigned to the work. However, all major and key milestones are shown, and the total BCWS in the planning package is considered to be part of the cost account BCWS total. Also a best estimate of time-phased resources (e.g., labor, material) must be a part of the planning package.

Planning packages must be converted progressively into task packages before the work in the planning package is scheduled to start. The planning system recognizes that not all tasks can be planned in detail at the start of the planning effort. Converting planning packages to task packages is done through formal change control.

Subcontracted work includes both onsite and offsite work and is considered to be a part of the Westinghouse Hanford baseline. This work is planned as separate task packages in cost accounts as appropriate.

The subcontractor's effort will be planned according to the type of effort, as follows:

1. Fixed price (pay on delivery)

BCWS is planned in the month of delivery as one lump-sum payment for one milestone.

2. Fixed price (milestone payment)

BCWS is planned corresponding to the accrual milestones.

3. Fixed price (equivalent unit delivery)

BSWS is planned according to the unit price and planned unit delivery per month.

4. Fixed price (progress payments)

BCWS is planned according to the progress payment plan.

5. Cost plus fixed fee

BCWS is planned according to the time-phased cost plan submitted to Westinghouse Hanford by the subcontractor and approved by Westinghouse Hanford.

6. Cost plus award fee

BCWS is planned according to the time-phased cost plan submitted to Westinghouse Hanford by the subcontractor and approved by Westinghouse Hanford.

The CAMs may have work in their cost accounts that must be accomplished outside their own organizations. When this is the case, the performing 
organization's manager and the CAM plan the effort together. The performing organization's manager shows agreement with the plan by signing the CAP document.

The total of the task package and planning package BCWS must equal the total assigned budget on the CAA. If any element of the CAP is inconsistent with the CAA (i.e., scope, schedule, budget), the CAM revises the CAP or negotiates a change to the CAA with the WBS activity-level manager.

The completed CAP is reviewed and signed by the CAM and the CAM's functional manager. It is forwarded to the WBS activity level manager with the CAA. The WBS activity level manager and the program administration or project control organization representative verify that the CAP is compatible with the CAA. The program and/or project manager then signs both documents and returns copies of the CAP to the CAM. The CAM then signs indicating final agreement with the planning. The incorporation of the approved CAP into the FDS with its appropriate charge code constitute the CAM's authority to begin work on the cost account.

For projects, the CAPs are prepared for the total duration of the capital equipment and project. They are not constrained by fiscal year. Where the work is far enough in the future that detailed task packages cannot be prepared, planning packages are used. The planning emphasis is on preparing detailed task packages for the current fiscal year. For the current fiscal year plus 1 year (CFY+1) the CAP is prepared including task packages and planning packages. For work beyond the $C F Y+1$, work may be summarized in planning packages.

\subsection{EARNED VALUE METHODS}

The concept of earned value is the heart of the MCS. Earned value is a method applied to measure the value of work accomplished and is compared with the value of work that was planned to be accomplished. If the planned work is constantly changing, performance measurement is lost. The earned value method provides an objective way to calculate progress toward program and/or project goals. Task package budgets are time-phased resource estimates. The CAMs assign the most appropriate earned value method to each task package so that an objective measurement can be made. To increase the value of any later analysis, the type of earned value method chosen must match the type of work being done. The MCS recognizes six methods, each of which is described below (Reference procedure WHC-CM-2-5, 2.2, Appendix B):

1. Milestone Method--This method is used when work can be measured by distinct events. These events should be specific, measurable, and important to the accomplishment of the cost account work. Each event is called a milestone and it represents the value of the planned resources to accomplish it. This method is used mainly where milestone tasks are sequential and where a milestone can be assigned every month. The earned value reported is then the completion of a milestone. 
NOTE: Including milestones appearing on the CAA in a task package does not limit the method to the milestone method.

2. Estimate of Percent Complete--This method is used when distinct milestones cannot be identified in each reporting period, but progress toward completion of a piece of work can be identified. Because this method is more subjective than the milestone method it is less desirable. Milestones may be shown throughout the task package, but they are for tracking purposes only, not for measurement.

3. Equivalent Units--This method is used for task packages that involve completion of a number of similar units of roughly equal value (e.g., capsules) over a period of time. The number of units divided into the total BCWS determines the unit value. The budgeted cost of work performed (BCWP) is then based on actual number of units completed times the planned value for each equivalent unit.

4. LOE--This method is used for work that does not readily lend itself to discrete measurement, doesn't result in a physical product, or is of an administrative or support nature (e.g., program management). The BCWP is always equal to the BCWS; therefore, there can be no schedule variance to give visibility to the work that has or has not been done nor any indication of how efficiently the work was done. Its use should be held to a minimum. In general, LOE should be held to 25 percent or less for the current fiscal year of the total dollar budget.

5. Modified Milestone--This method is used when there are one or more months between milestones. This method provides more flexibility in how work is planned, but it does require a degree of subjective assessment of status. For this method BCWP is based on the completion of a milestone or the percentage of completion of the next occurring milestone.

6. Apportioned Effort--This method is used when work is dependent on or related in direct proportion to the performance of other welldefined work. Apportioned effort is established as a separate task with its own BCWS based on a percentage of the related work's BCWS. The related work must be identified on the CAP.

\subsection{WORK AUTHORIZATION}

Upon approval of the CAA and upon approval of the CAP in the FDS master file, the charge codes are listed as valid. This opens the task package and authorizes cost to be incurred for work performed. The performing organization manager (for a task package) can request help from another organization and simply have that organization charge to the task package control number (TPCN) by allowing cross charging to occur. This is a controlled process within the FDS. This eliminates the need to write a separate task or issue an internal work order. 
Work is also authorized for projects as described above but requires additionally the receipt of the project authorization from DOE-RL. The work as described on the project authorization is structured by the WBS and authorized by Westinghouse Hanford at the cost account level.

Work authorization for capital equipment not related to construction (CENRTC) starts with approval of the CAA. The CAPs are then written against the CAA.

\subsection{WORK COMPLETION}

Upon completion of the work the CAM closes the CAP in the FDS master file by inserting the completion date. The FDS will not accept charges made to a completed CAP.

\subsection{WORK STATUSING}

In order to obtain an objective evaluation of cost and schedule performance, the CAM measures the status of all planned work each month. This consists of determining BCWP for each task package. The CAM obtains the work status from each organization that is performing work on the cost account. Status is entered on the Task Package Status Input (TPSI) and submitted to Program and Project Control. The BCWP is calculated and entered into FDS by Program and Project Control. (Reference procedure WHC-CM-2-5, 3.1, Appendix A.)

The CAMS who have subcontracts and/or materials within their cost accounts are responsible for measuring the performance of those task packages. Performance should be based on subcontractor reports and material information provided by the procurement and subcontract organizations. When vendor and subcontractor reports are not detailed enough to provide the necessary performance information, the CAM assesses performance based on visual inspection and the latest data available. 
WHC-EP-0388

This page intentionally left blank.

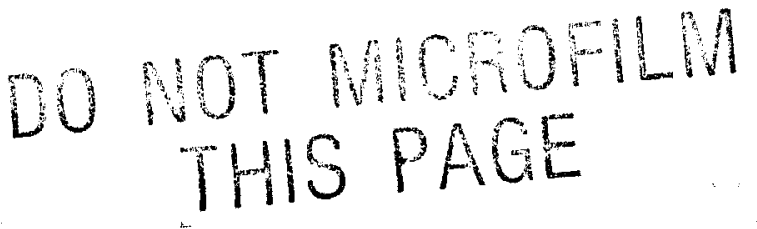




\subsection{ACCOUNTING}

\subsection{DATABASE DESCRIPTION}

\subsubsection{Financial Data System}

Westinghouse Hanford uses the FDS automated accounting system. The FDS interfaces with several source-data feeder systems that collect and maintain files feeding financial information to FDS (Figure 5-1). The FDS itself is composed of several "modules" that validate codes, price labor, calculate overheads, adders and taxes, and build records from the source financial records (both external and internal). Reports are generated to manage the financial responsibilities of Westinghouse Hanford. (Reference procedure WHC-CM-2-10).

Each of the following modules is documented in Westinghouse Hanford internal publications:

- FDS Cost

- FDS Capital

- FDS Budget

- FDS Work Order

- FDS General Ledger

- FDS System Administration

- FDS Expense

- FDS Performance Measurement.

\subsection{ELEMENTS OF COST}

Cost is identified by a series of three codes that are entered on all source documents: an organization code, a cost element code, and a charge code.

- The organization code identifies the functional organization that incurred the cost. The codes are structured in a hierarchical fashion to identify the organization from the division or department down to the lowest level unit.

- The cost element code describes the type of cost incurred (e.g., labor, material, or purchased services).

- The charge code identifies the funding source for the cost. All charge codes are established through the WBS to identify the specific task to which the cost is applicable.

The FDS interfaces shown in Figure 5-1 identify the input and the output of the FDS. 


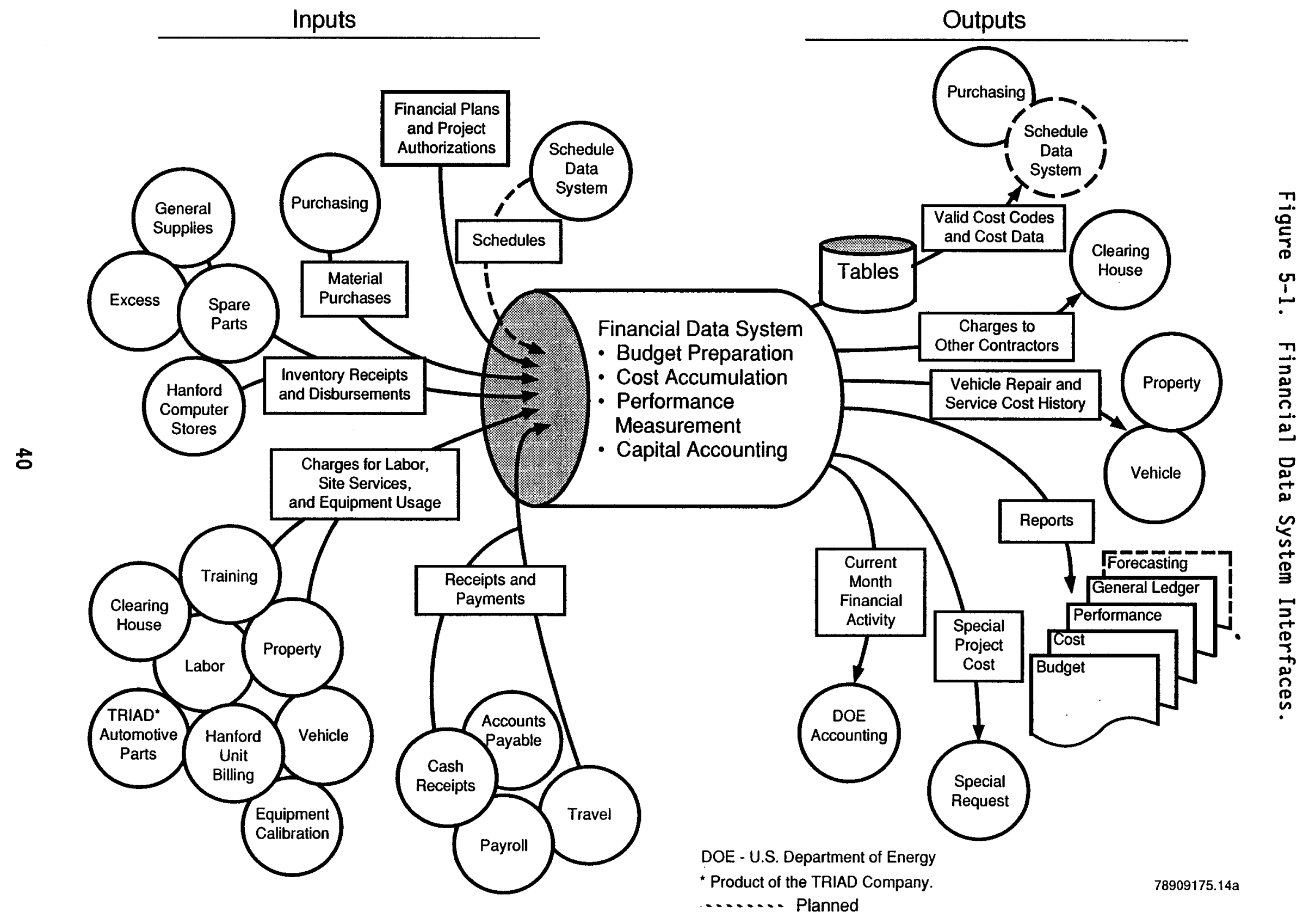




\subsection{ORGANIZATION CODE STRUCTURE}

Organization codes are used in BCWS and actual cost of work performed (ACWP) to identify the functional organization responsible for the incurred cost. Every organization code is composed of five characters and is structured in the following manner:

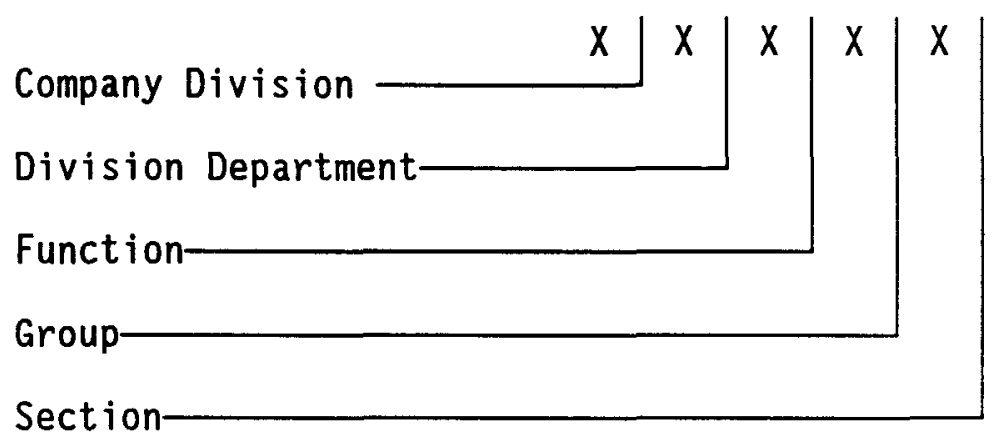

Example:

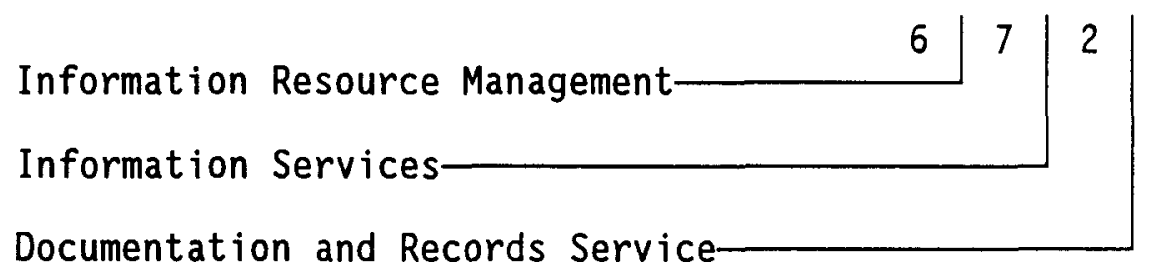

Records Management and Site Records-

DOE Correspondence and Commitment Control

The FDS requires that records entering the system contain the organization code. All organization codes are maintained on a controlledaccess table within the FDS. The table is used within the FDS to edit records for validity.

\subsection{COST ELEMENT STRUCTURE}

Cost element codes are used in BCWS and ACWP to identify types of costs. Every cost element is composed of three characters and is structured in the following manner:

Family
Group
Specific


Example:

\section{(1)}

Material

(15) Shop and Laboratory Supplies

These cost element levels are defined as follows:

- Family--This is the first of three positions and is used to define the type of cost at its highest level (e.g., salaries [0], material [1], purchased services [2]).

- Group--This level uses the second position to provide finer distinctions within an account family (e.g., office supplies [14], shop and laboratory supplies [15], direct and applied material [10]).

- Specific--The third position allows a finer distinction within the groups (e.g., protective clothing [152], masks and mask parts [154]), where the distinction is necessary for functions such as rate analysis and control. Where a cost element is required on a cost input document, it is always entered at the three-digit level. Budgeting input is an exception as it is input at the two-digit level.

The FDS either assigns the cost element based on system logic or requires that data entering the system contain the cost element. All cost element codes are maintained on a controlled access table within the FDS. The table is used within the FDS to edit cost elements for validity.

\subsection{CHARGE CODE STRUCTURE}

Charge codes are used in BCWS and ACWP to classify cost against a defined work scope. All costs are recorded using the WBS at lowest level, the TPCN, as shown in Figure 5-2.

There are two valid charge codes that can be recorded on FDS input documents:

- TPCN--A TPCN is a five-digit code that has a one-to-one relationship to the ten-digit WBS task-package code. The FDS maintains a controlled table of WBS codes and corresponding TPCN codes. 
Figure 5-2. Work Breakdown Structure Charge Codes.

\section{WBS Code Structure}
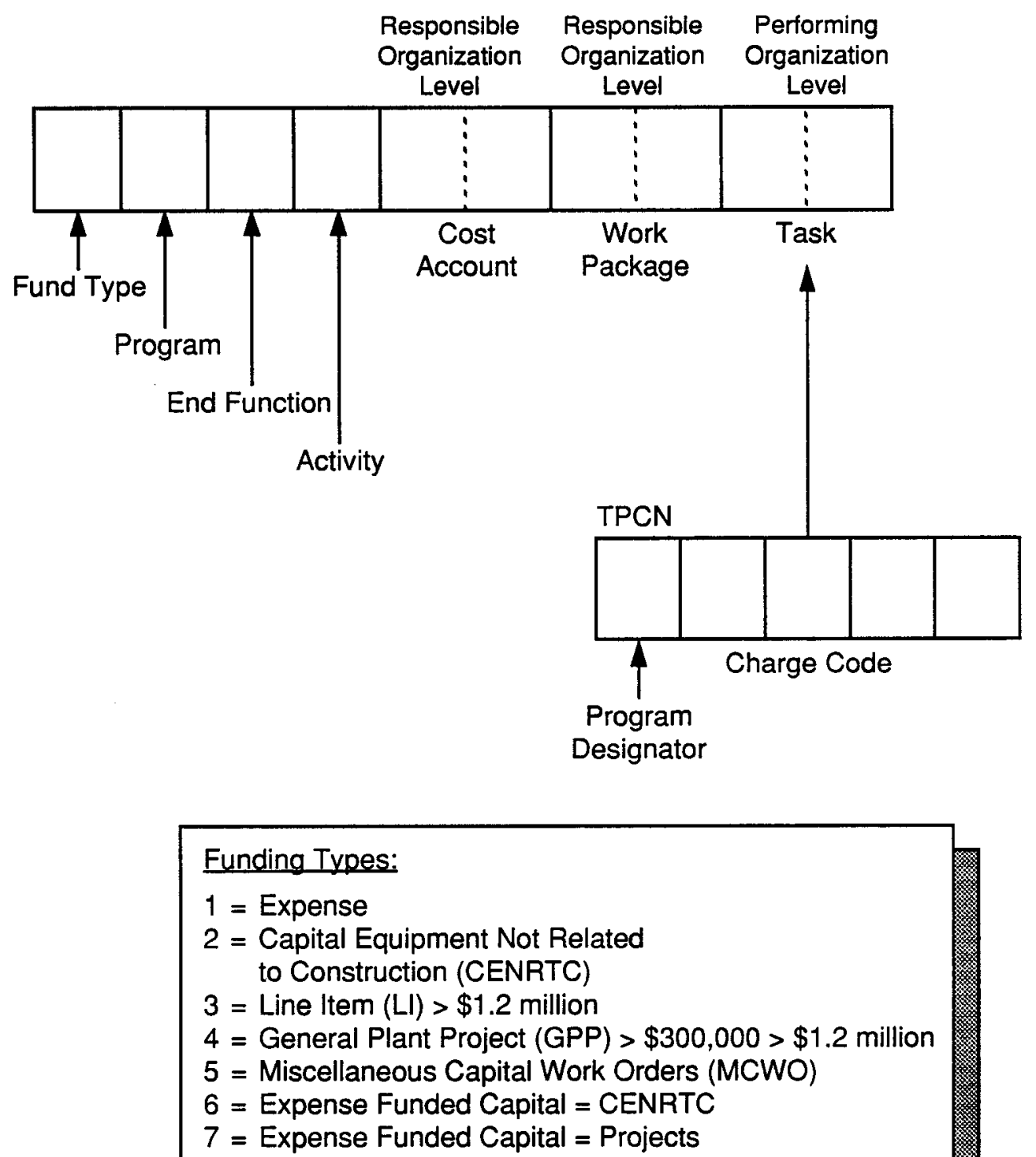
- Work-order number--Work orders may be used in the FDS cost module as an additional method of recording and reporting costs. Valid work orders are maintained on the FDS controlled-access work-order table. Each work order is associated with a TPCN. Charges to a work order result in charges to the associated TPCN via FDS logic.

\subsection{CLASSIFICATION OF COSTS}

\subsubsection{Direct Costs}

Direct costs consist of labor, material, and other costs that can be practically, consistently, and specifically identified with a final cost objective.

Direct labor costs are supported by time distribution reports (TDR) prepared by employees. The TDRs are signed by the employee's supervisor.

Material costs are traceable via purchase requisitions, purchase orders, receiving documents, invoice approval and payment records, and store order documents.

Other costs are costs specifically identified to the product or service being rendered that are neither labor nor material. Examples include travel, computer time, agency labor, vehicle usage, and laboratory and testing services.

\subsubsection{Indirect Costs}

Indirect costs are costs that cannot be identified to a single cost objective. These costs are accumulated in overhead or intermediate cost pools for distribution to end objectives. Each pool has a defined base of direct and indirect cost over which the pool costs are distributed. Predetermined annualized rates are applied to base dollars to distribute overheads. The overhead rates are added sequentially to the base.

Indirect costs are accumulated within the FDS so that a comparison can be made between budgeted and actual costs.

5.6.2.1 Organization Overhead. Organization overhead pools are used to distribute the overhead costs of the performing divisions or departments. The distribution from the pools comes from applying a predetermined rate to all direct labor expenditures as calculated from the TDRs, using average labor rates. Costs are composed of resources such as management, secretarial support, office supplies, telephone, physicals, and general training, which are not identifiable to a specific program. Rates are applied to all direct labor incurred by the function at a standard percentage. 
5.6.2.2 General and Administrative overhead. The general and administrative (G\&A) overhead pool is used to distribute the costs of company-wide support organizations within Westinghouse Hanford. The distribution from the pool comes from applying a predetermined, annualized rate to all direct base charges, including organization overhead for Westinghouse Hanford expensefunded program charges to other Hanford Site contractors and the DOE-RL. Exceptions are that G\&A is not applied to charges from other Hanford Site contractors, expense-funded projects, or capital-funded activities. The following are typical examples of the G\&A pool components:

- Accumulations--Composed of all costs associated with Company-wide support organizations:

- President and Vice-President Offices

- Public Relations (excludes dedicated project personnel)

- Human Resources (excludes cooperative education students and administrative review personnel)

- General Counsel (includes audit, excludes dedicated project personnel)

- Information Resource Management

Finance and Budgets

Personnel Liaison

Secretarial Support

Program Planning and Control

Management and Operations Mail Services

Management and Operations Records and Document Control

- Controller

- Safety, Quality Assurance, and Security

Emergency $\mathrm{Planning}$

Personnel Security

Classification Officer

- Contract Fee 
- Distribution

- Distributed to direct activities through a G\&A rate

- Rate is calculated based on distribution to all operating expenses (including organizational overhead) except expenses incurred by G\&A functions, excluded from G\&A application by DOE directive, or associated with capital line items, capital equipment, and general plant projects.

5.6.2.3 Common-Support Pool. The common-support pool (CSP) is used to distribute costs for site-wide services provided by Westinghouse Hanford and DOE. The following are examples:

- Fire Department

- Road Maintenance

- Hanford Science Center

- 600 Area Landlord

- Fuels Material Extraction

- Facility

- Technical and Legal Library

- Cultural Resources

- Environmental Support and Oversight

- Emergency Preparedness G\&A

- Meteorology

- Oversight Activities.

The distribution from the pool comes from applying a predetermined, annualized rate to all direct base charges including organization overhead, except expenses excluded from CSP application by DOE directive, expenses incurred in support of other contractors, and expenses associated with capital line items, capital equipment, and general plant projects.

Figure 5-3 illustrates how the various rates are applied.

5.6.2.4 Company Rate Evaluation. Company rates are maintained within the FDS on controlled-access tables. Rates are established by the Controller's Department and approved by executive management. All rates are reviewed annually and monitored monthly. Adjustments are normally made prospectively, not retroactively. Figure 5-4 illustrates the process flow. (Reference procedure WHC-CM-2-5, 1.5.)

Internal service cost pools are used to accumulate and distribute the cost of many site services. Pools are established as required using WBS codes for each service center (e.g., Facilities Utilization, Electrical Utilities, Fleet Management, Graphics Service). The accumulated cost is distributed to the internal customers of each service center with the appropriate charge code (work order or TPCN) for the cost to be distributed. Distribution (1iquidation) of cost may be based on units of service, percentage of service used, or other approved basis for each service. Distribution of cost may be accomplished with a detailed ledger entry (DLE) or automated billing system transaction. 
WHC-EP-0388

Figure 5-3. Rate Accumulation Example.

\begin{tabular}{|c|c|c|c|}
\hline Cost Element & Example Rate & Amount & Application Base \\
\hline $\begin{array}{l}\text { Exempt Labor } \\
\text { (Organizational Average) }\end{array}$ & & $\$ 100.00$ & \\
\hline Labor Absence Adder & $\begin{array}{c}14 \% \\
(100 \times 0.14)\end{array}$ & 14.00 & Salary Base \\
\hline Continuity of Service & $\begin{array}{c}30.5 \% \\
(114 \times 0.305)\end{array}$ & 34.77 & $\begin{array}{l}\text { Base + Absence } \\
\text { Adder }\end{array}$ \\
\hline Total Labor Costs & & $\$ 148.77$ & \\
\hline Organizational Overhead & $\begin{array}{c}20 \% \\
(148.77 \times 0.20)\end{array}$ & 29.75 & Total Labor Costs \\
\hline $\begin{array}{l}\text { General and } \\
\text { Administrative }\end{array}$ & $\begin{array}{c}18.5 \% \\
(178.52 \times 0.185)\end{array}$ & 33.02 & $\begin{array}{l}\text { Total Labor + } \\
\text { Organizational } \\
\text { Overhead }\end{array}$ \\
\hline Common-Support Pool & $\begin{array}{c}7 \% \\
(178.52 \times 0.07)\end{array}$ & 12.49 & $\begin{array}{l}\text { Total Labor }+ \\
\text { Organizational } \\
\text { Overhead }\end{array}$ \\
\hline Total Cost & & $\$ 224.03$ & \\
\hline
\end{tabular}


Figure 5-4. Rate Evaluation Process Flow.

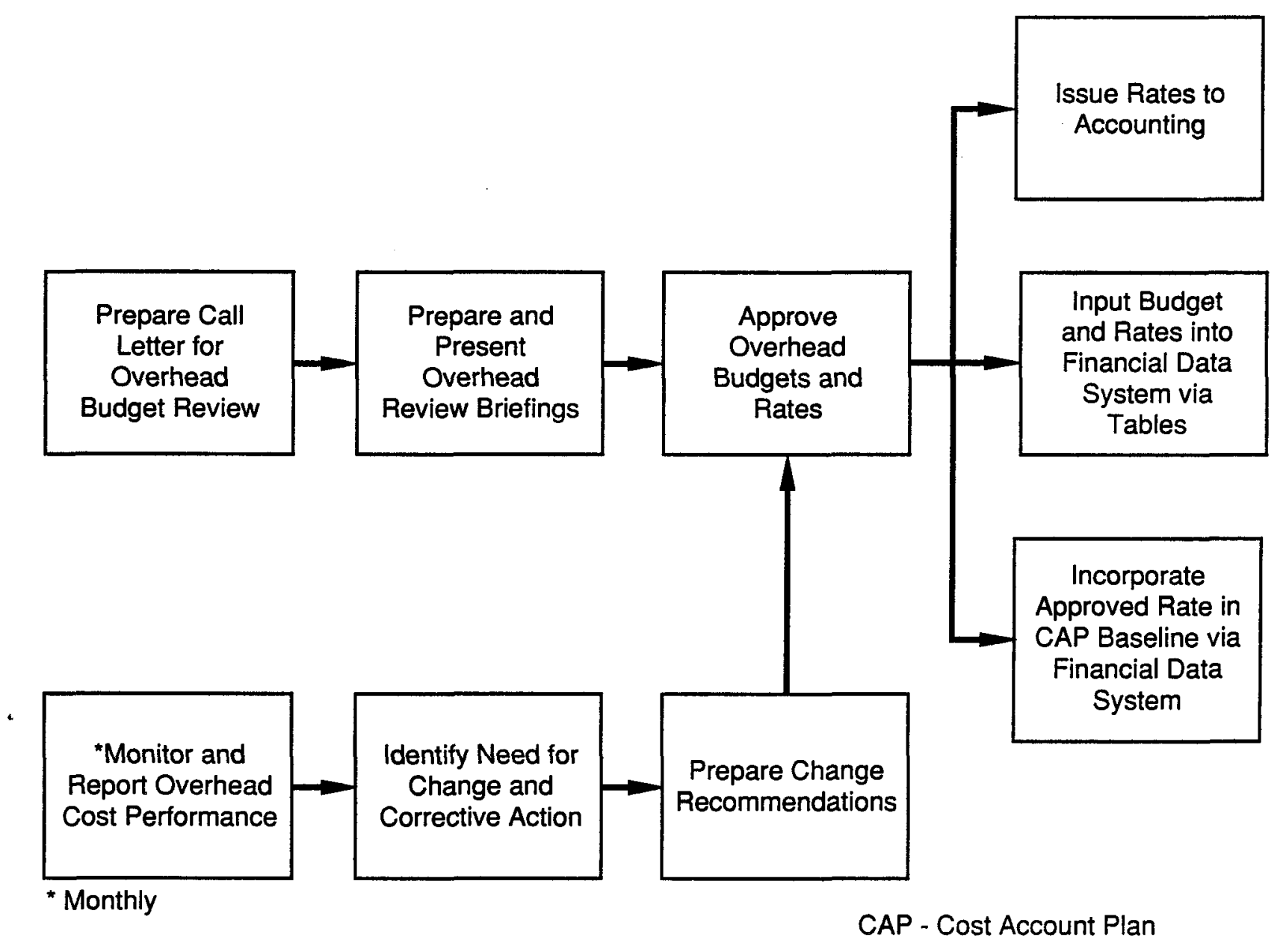

R9006160.6 
The Hanford Unit Billing (HUB) System is an automated billing system that provides summarized transaction records to the FDS for many of the interna? service cost pools. Rates for the service costs distributed by HUB are maintained within the HUB system on controlled-access tables.

Costs of service pools that do not use the HUB system are liquidated to customer charge codes via DLEs or transactions from small feeder systems (e.g., Hanford Computer Store System, Training System) feeding FDS. Rates are established by the organizations that provide the internal service in cooperation with the Controller's Department. All rates are reviewed annually and monitored monthly. Adjustments are normaliy made prospectively, not retroactively.

\subsection{MATERIAL COST CONTROL}

Material requirements are fulfilled by withdrawal from inventory (store orders) or direct purchase (purchase orders). Store orders are completed for withdrawals from either general supplies or spare parts inventories. Valid organization codes, cost elements, and charge codes are recorded on the store order. Cost (i.e., ACWP) is generated at the time the material is disbursed. Direct purchases are initiated on requisitions, which migrate to purchase orders and require the same cost coding as store orders. Direct purchases are costed at the time the material is received and accepted by Westinghouse Hanford. Service orders are costed upon invoice processing. The BCWS for material acquisitions are time phased to correspond to the delivery or use of the item. Westinghouse Hanford uses the average cost method plus applicable adders for valuation of supplies and or spare parts inventory and the unit price reflected on the purchase order for direct purchases.

Material costs for both purchase orders and store orders receive an overhead adder, known as the material procurement rate (MPR) adder. The MPR is used to help fund the Procurement and Materials Management Function including purchasing, receiving, warehousing, and delivery. Three separate MPR rates have been established: (1) the rate applied to inventory withdrawals, (2) the rate applied to direct-purchased material, and (3) the rate applied to major subcontracts, automated data processing equipment (ADPE) fuels, essential materials, and service purchase orders. The MPR structure is maintained on access-controlled tables in the FDS. Rates are established by the Controller's Department and approved by executive management. The rates are monitored monthly and, if needed, are adjusted prospectively, not retroactively.

\subsection{PURCHASE ORDER SYSTEM}

All purchases begin with the completion of a purchase requisition. Cost and Commitment Accounting reviews each applicable order for proper cost coding and appropriate signature authorization. The purchase requisition is entered into the Purchasing Information Documentation System (PIDS) where it is upgraded into a purchase order when a vendor and price is established. The PIDS provides all purchasing-related information, including accrual input via 
a feed to the FDS. The combined capabilities of the two systems allow identification of material cost variances by price and or usage. Each order of material (except supplies inventory) is coded to the appropriate WBS to simplify performance measurement. General supplies inventory items are accounted for in the Warehouse Inventory Management System (WIMS). This system maintains a record of supply items and uses an average-cost basis for costing the items. The WIMS feeds FDS with inventory-type items. General supplies items are costed to a WBS code when they are requisitioned from the inventory account. 
WHC-EP-0388

\subsection{ANALYSIS AND REPORTING}

The performance analysis and reporting process is used to analyze significant deviations from planned work, to develop any necessary work-around plans so that unfavorable deviations can be minimized, to develop revised estimates at completion when the deviations cannot be minimized, and to provide the data necessary for both internal and customer reports. The major steps of the performance analysis and reporting process are shown in Figure 6-1. (Reference procedure WHC-CM-2-5, 3.1.)

\subsection{VARIANCE ANALYSIS}

Each month the FDS provides reports showing the cost and schedule performance of each cost account, each upper-level WBS element and each functional organization for all work performed for the DOE-RL at the Hanford Site. Some deviation of performance from the plan is expected. These deviations are called variances and are the objects of variance analysis.

\subsubsection{Variance of Concern}

The following three variances are generated as products of the MCS: cost variance (CV), schedule variance (SV), and at-completion variance (ACV). The manner in which the variances are calculated and how they relate to each other is shown in Figure 6-2. Each variance is also discussed briefly below.

- Cost Variance--This variance indicates if the value of the work actually completed is more or less than was budgeted for that work. It is determined by subtracting the ACWP from the BCWP. The cost variance compares the value of the work completed to the actual cost incurred. A negative variance signifies an unfavorable position, while a positive variance indicates a favorable situation. The cost variance can be expressed in terms of dollars or as a percentage of BCWP.

- Schedule Variance--This variance indicates that the value of the work actually completed is more or less than the value of the work that was scheduled for completion. It is calculated by subtracting the BCWS from BCWP. The schedule variance compares the value of the work completed to the value of the work planned. A negative variance indicates a behind-schedule condition, while a positive variance indicates an ahead-of-schedule condition. The schedule variance can be expressed in terms of dollars or as a percentage of BCWS. Additionally, project schedules are analyzed including activities, major and key milestones, and project status with significant variances reported.

- At-Completion Variance--This variance indicates if funds will be sufficient to cover the work planned. It is calculated by 


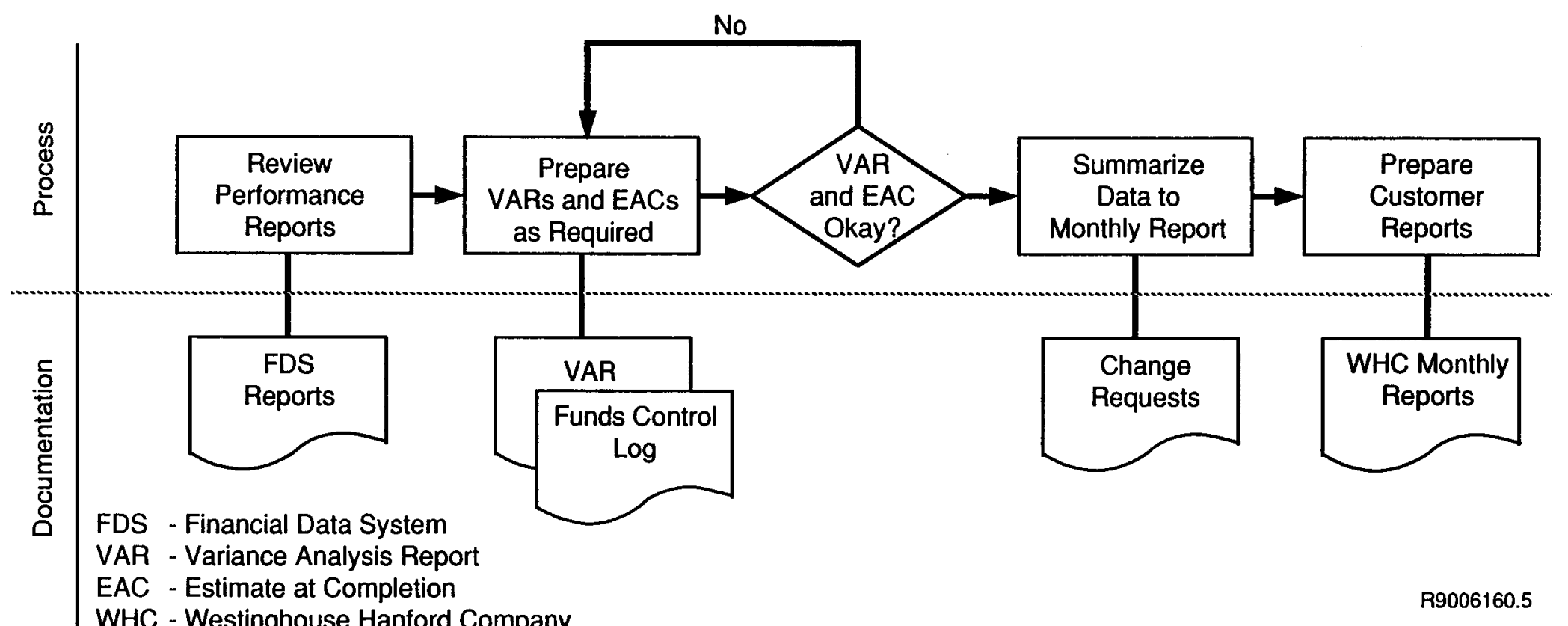

WHC - Westinghouse Hanford Company 
Figure 6-2. Variances as a Product of the Management Control System.

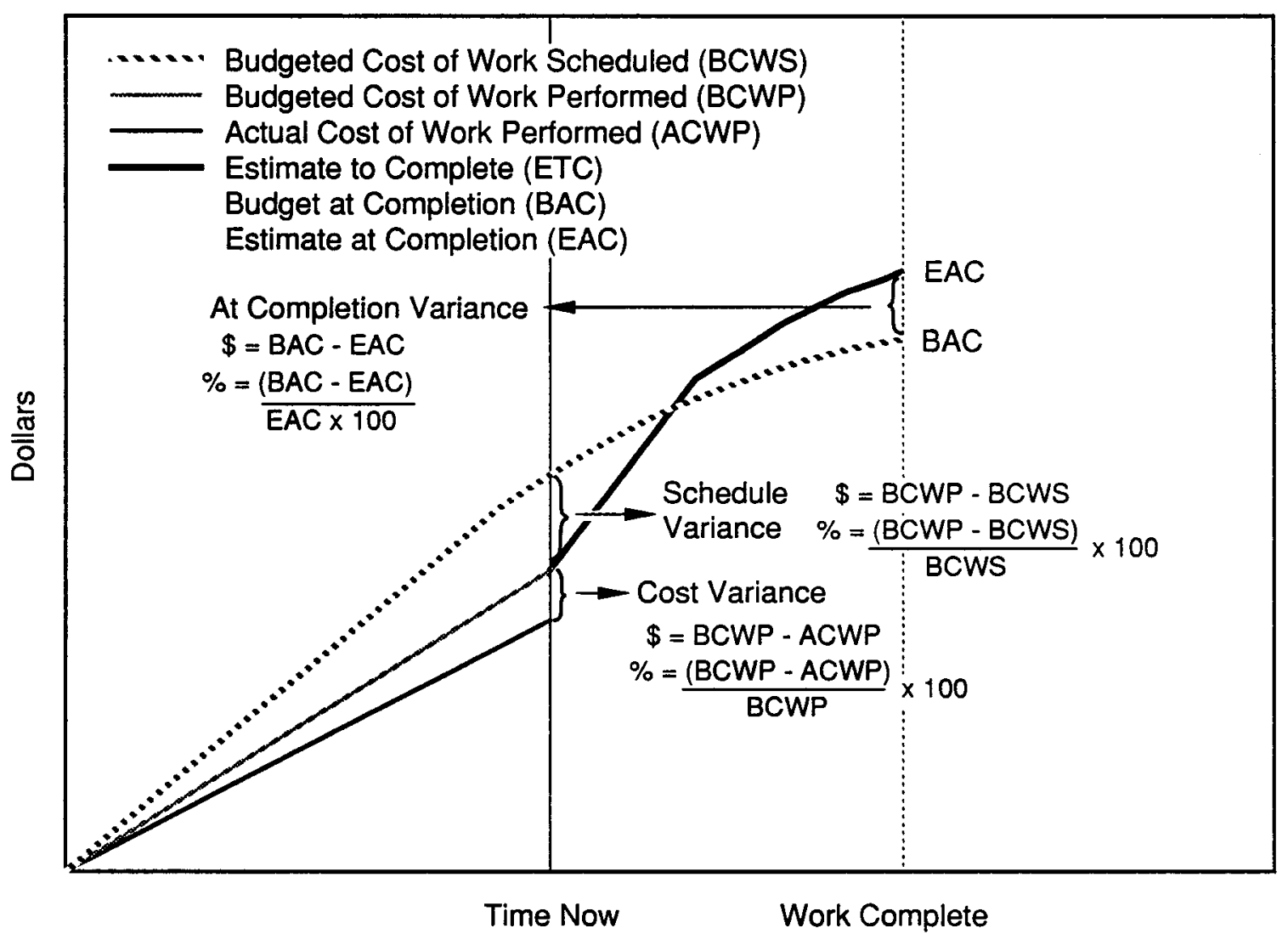

R9006160.1 
subtracting the $E A C$ from the $B A C$. A negative variance indicates that more money must be made available or work scope reduced, whereas a positive variance signifies a lower total cost than expected.

\subsubsection{Variance Thresholds}

To provide for management by exception, percentage and dollar thresholds have been developed for each level of performance measurement from the costaccount level to the program- and/or project-reporting level. Only those variances that exceed the thresholds require the development of a formal variance analysis report. The following are minimum thresholds assigned for all variances; the program and/or project manager or the customer can impose more stringent thresholds if desired:

- BCWS under $\$ 500,0000= \pm 10 \%$ and $\pm \$ 10,000$

- BCWS over $\$ 500,000= \pm \$ 50,000$.

Even favorable variances need to be examined, especially as they may be indicative of underruns that may trigger preparation of an EAC. The EACS on the FDS give the WBS activity level managers and the program and/or project managers indications of excess or insufficient funds.

\subsection{PREPARATION OF VARIANCE ANALYSIS REPORTS}

The budget analyst initiates a VAR for each cost account exceeding the thresholds. The VAR is completed by the CAM, who reviews the variances indicated; conducts an in-depth analysis of the problems, causes, and impacts; and develops a corrective action plan.

- Identification of Contributing Causes--The focus of the variance analysis is to identify contributing factors of the variance so that appropriate action may be taken. To communicate the causes clearly, the CAM addresses the SV and CV separately. Causes are quantified by type of cost (cost element) to ensure that every aspect of the problem is being addressed.

- Potential Impact Analysis--The potential cost, schedule, and workscope consequences of the variances must be explained by the CAM in the VAR. This includes the impact on the cost account, interfacing organizations, other cost accounts, and on the overall project

objectives. Determination of impact helps management establish the priority of requests for changes, assess the need for work-around plans, make decisions about reallocation of resources, and take other corrective measures. This analys is also should document the impact if corrective action is taken. Impact and corrective action must only be identified and reported once. 
- Corrective Action Plan--The corrective action plan is an important part of the VAR, because it proposes a specific plan of action to eliminate or minimize the impact of the existing variances. The proposed action should include the responsible individual or organization who should take action and a schedule for completion of each action. If actions are required by people or organizations out of the managerial control of the CAM, mutual agreement should be obtained. The CAM also should provide a forecast of the effect the corrective actions will have on the variance (i.e., reduced, sustained, eliminated). In addition, the CAM should report previously implemented corrective actions. The corrective action plans are guides for potential further management decisions that may be effected through the change control system.

After completion of the VAR, the CAM should review the report with his functional manager before submitting it to the WBS activity-level manager. The functional manager should review the VAR for completeness and to determine if any proposed action can be attained.

Other DOE contractors, who support Westinghouse Hanford and maintain their own performance measurement system, provide Westinghouse Hanford with all necessary reports and data to incorporate into customer reports. The Westinghouse Hanford manager responsible for the appropriate WBS element will coordinate with the other DOE contractors and subcontractors to ensure data received are consistent with the requirements of the Westinghouse Hanford MCS.

\subsection{PRICE AND USAGE VARIANCE}

When material is a prime contributor to a significant $\mathrm{CV}$, the components of the CV must be separated into price and usage variances. A material price variance occurs when the budgeted unit price of an item differs from the actual unit price costed. It is calculated by subtracting the actual unit price from the budgeted unit price and multiplying that figure by the budgeted quantity. Although Procurement and Materials Management identifies significant price variances for individual items at the time each purchase order is placed, the CAM is responsible for analyzing the effect of the variances on the scope, schedule, and budget of the affected cost accounts. The CAM compares the original budgeted amount for the material work package with the actual cost of the material received. A material usage variance occurs when the quantity of an item received differs from the quantity budgeted. It is calculated by subtracting the actual quantity from the budgeted quantity and multiplying that figure by the budgeted unit price.

\subsection{ESTIMATE AT COMPLETION}

The information obtained during the analysis cycle provides the basis for projecting final costs. The process of providing an EAC is linked to the process of analyzing variances; whenever variance impact is determined, the validity of the EAC is examined. (Reference procedure WHC-CM-2.5,3.2.) 
When work on cost accounts begins, the BAC and the EAC are equal. As work progresses and various performance trends develop, the trends may show that work cannot be accomplished within the existing budgetary targets. In such situations, a prediction of the final cost, or an EAC, is developed to forecast the possible overrun or underrun. The EAC, at the cost account level, is calculated for the length of the cost account. The EAC is calculated by adding the actual cost of work performed to date and an estimate to complete (ETC) the remaining work. When recording ACWP for the purposes of an EAC, care must be taken to ensure that all current charges have been included. In addition, check to ensure that no corrections to the ACWP, either for labor mischarges or missing labor costs, must be made. When the EAC on the VAR is approved by the activity manager, the EAC is input into the FDS by the budget analyst.

The CAM examines the cost account EAC monthly as part of the variance analysis process. If it appears that the old EAC represents an unobtainable target, the CAM makes a revision to the EAC on the VAR and the EAC is entered into the FDS when approved. Such an examination may occur even though the cost account is within the variance thresholds.

Regardless of why EACS are revised, they are not incorporated until they have been reviewed and approved. Approval of an EAC by the WBS activity-level manager authorizes the entry of the EAC into the FDS. The WBS activity-level manager may allow the CAM to spend to the EAC but must monitor funds expended to prevent any overrun. A revised EAC does not change the BCWS for that work unless further action is taken through the change control system. When a revised EAC has resulted in a budget change, the change will be handled through the change control system and an updated CAA given to the CAM.

The FDS provides rollup reports at various levels of the WBS; thus, an EAC for the total project or any portion thereof can be assessed as required using the FDS performance reports.

\subsection{CUSTOMER REPORTING}

Customer reporting requirements shall be in accordance with the Annual Operations Directives, DOE Order 1332.1A, Uniform Reporting System, and the Reporting Requirements Checklist provided by the DOE (DOE 1985). Performance reports from FDS provide the necessary summarized data to prepare the formatted cost performance reports specified in DOE Order 1332.1A and any other cost- and schedule-related performance desired by the customer.

\subsection{TREND ANALYSIS}

The ultimate goal of any undertaking is to produce a product that is technically acceptable, on schedule, and within budget. To accomplish this the status must be regularly reviewed and future requirements must be objectively forecast. This can be accomplished by performing periodic trend analysis using historical data. Analysis of cost and schedule trend patterns has proved to be one of the most accurate methods of estimating cost of the 
contract at completion for on-going projects. The following is an approach to trend analysis. (Reference procedure WHC-CM-2-5,3.1.)

1. Examine current and historical performance data for trends.

2. Interpret and draw conclusion from the trends.

3. Use the trends, interpretations, and conclusion to predict future positions.

4. Refine predicting approaches based on results to better predict a future position.

There are three performance indexes that parallel the previously

mentioned variances. The cost performance index (CPI) is derived on a monthly and a cumulative basis from the FDS performance reports by dividing the amount reported for the BCWP by the ACWP. This indicates the cost efficiency with which work has been accomplished to date. The equation is structured so that 1.0 is "as planned" or normal; above 1.0 is better than normal; and below 1.0 is less than normal.

The schedule performance index (SPI) also can be derived from the FDS performance reports by dividing the BCWP by the amount for the BCWS. This indicates the schedule efficiency at which the work has been accomplished to date. Normal here is also 1.0 .

The to-complete performance index (TCPI) is calculated by dividing the difference of the BAC less the cumulative BCWP by the difference of the latest EAC less the cumulative ACWP. The results of the formula are a comparison of the work remaining to the amount of estimated costs remaining. This shows the cost efficiency that must be attained to do the remaining work within the EAC. If the result of the formula is greater than 1.0 , that means work must be more than $100 \%$ efficient to stay within the EAC. If our past performance index is $<1 \%$ or $\geq 100 \%$ we should have serious doubts about achieving the EAC.

\subsection{FUNDS MANAGEMENT}

The MCS differentiates between the terms "budget" and "funds." Budget is the planned and approved estimate of resources (measured in labor dollars, or labor and material dollars, hours or units) required to complete a specific scope of work within a given period of time (i.e., BCWS). Funds are the actual dollars authorized by the DOE financial plans, project authorizations, internal funding requests, and contingency. These funds are maintained and controlled within the FDS at the budget and reporting (B\&R) and/or program level as authorized funding.

In the beginning, "budget" and "funds" requirements are equal. However, as the work progresses, departures from what was foreseen during the time the budget was constructed probably will occur. These departures are evident by variances within the earned value performance measurement indicators. Analysis of these variances is completed by the CAM, and trending of the 
various CAPs is performed over time with over and under conditions noted. Changes to the funds required to complete the work are documented by revisions of the EAC. Only when authorized changes to work scope or schedule are made does the corresponding budget change. Increases to authorized funding are handled through the change control process.

A Budget and Funds Control Log (refer to the example presented in Figure 6-3) is established at the beginning of a project by the project control organization. The Budget and Funds Control Log provides the history of management reserve, undistributed budget, contingency, and performance measurement baseline transactions during the project. Entries to the log provide an audit trail back to the source of budget changes. Total values for each cost account are maintained in the $10 \mathrm{~g}$, with references made to timephased budgets.

The proper use of funds management can greatly decrease the number of change requests that must be processed and keep intact the performance measurement baseline; thus, the total performance is given greater visibility. Continually changing the BCWS within a task package will mask performance and hide schedule and budget problems. (Reference procedure WHC-CM-2-5, 2.4.) 
EXPENSE - BUDGET AND FUNDS LOG

HANFORD WASTE VITRIFICATION PLANT (HWVP) PROJECT

$$
(\$ 000)
$$

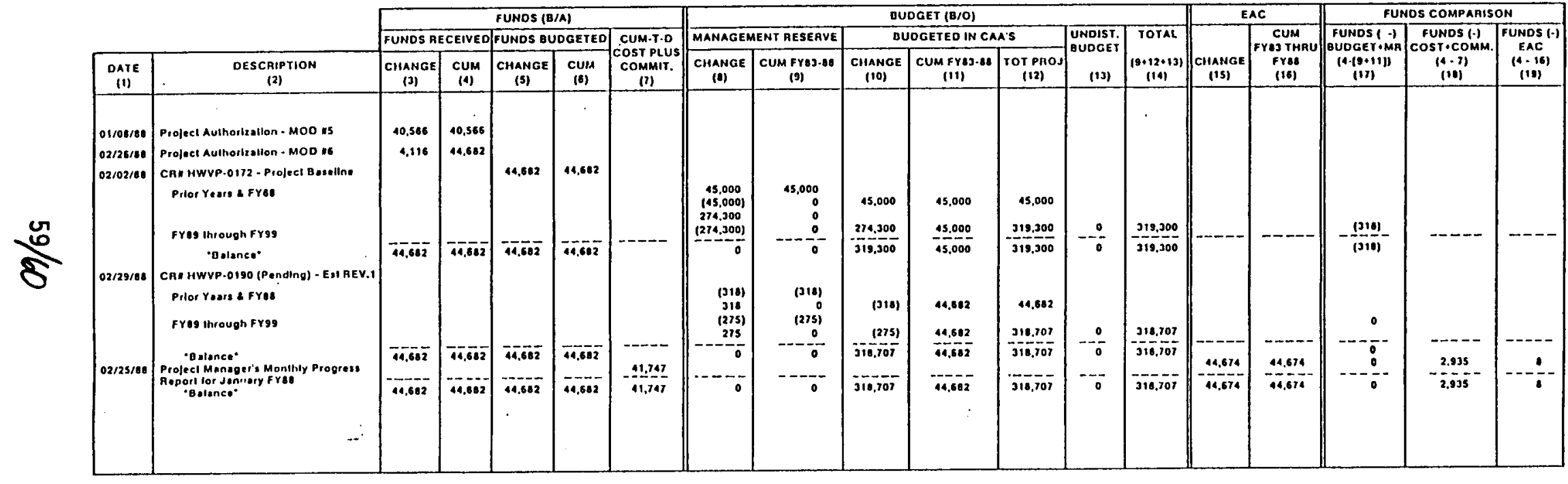


WHC-EP-0388

This page intentionally left blank.

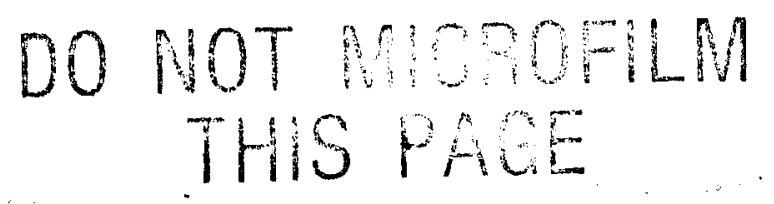




\subsection{CHANGE CONTROL}

The change control system ensures adequate documentation and control over work scope, schedule, funding, and associated budget changes. (Reference procedure WHC-CM-2-5, 4.1.)

The initial cost account planning results in the establishment of the PMB. Modifications caused by changes in program requirements, design developments, or desired improvements, are made to the PMB through the change control system (Figure 7-1). The process allows for the orderly handling of formal changes. This process has four primary objectives:

- Incorporate baseline changes in a manner that maintains clear traceability back to the approved baseline that existed before the change.

- Incorporate changes in a timely manner.

- Plan the work only for those changes that have been reviewed and authorized.

- Perform the work only on those changes that have been approved and properly planned.

Changes are classified according to the impact on the cost, schedule, and technical baselines. In general, the change classifications are as follows:

- Class I--This class involves changes to the budget, schedule, and technical baselines and scopes of work prescribed or approved by DOE.

- Class II--This class involves changes to the budget, schedule, and scope of work controlled by Westinghouse Hanford that do not fall into the Class I category.

- Class III--This class involves changes to the CAP without affecting the budget, scope, or schedule as defined in the authorizing document (i.e., CAA).

Project-specific criteria may be contained in individual PMPs.

\subsection{CHANGE IDENTIFICATION AND ANALYSIS}

A change can be requested by anyone involved in a program or project for any baseline element (e.g., budget, scope, schedule) by using a change request (CR) form (refer to the example presented in Figure 7-2). The change is identified and described and all impacts associated with the change are 


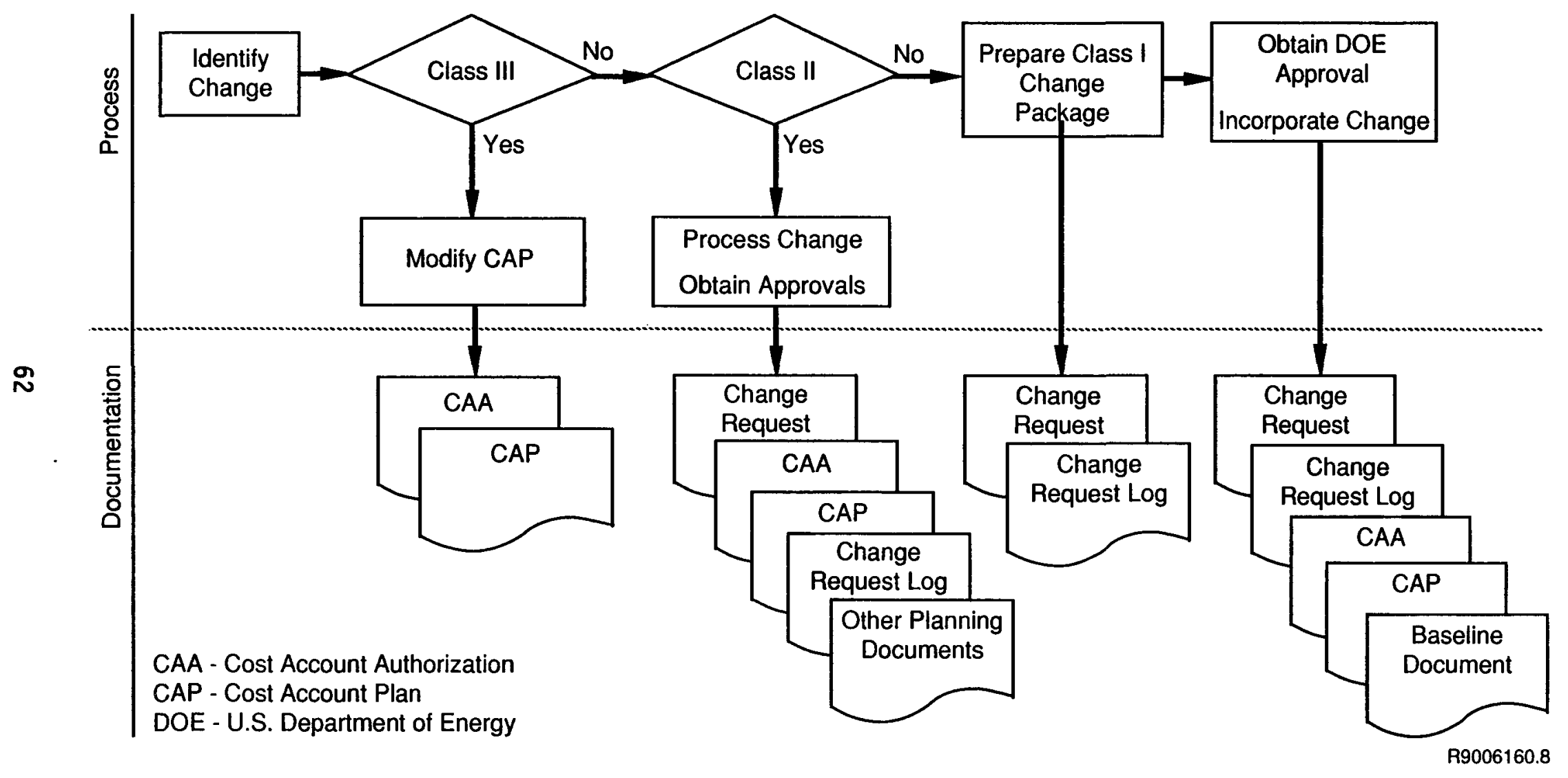


Figure 7-2. Example of Change Request Form.

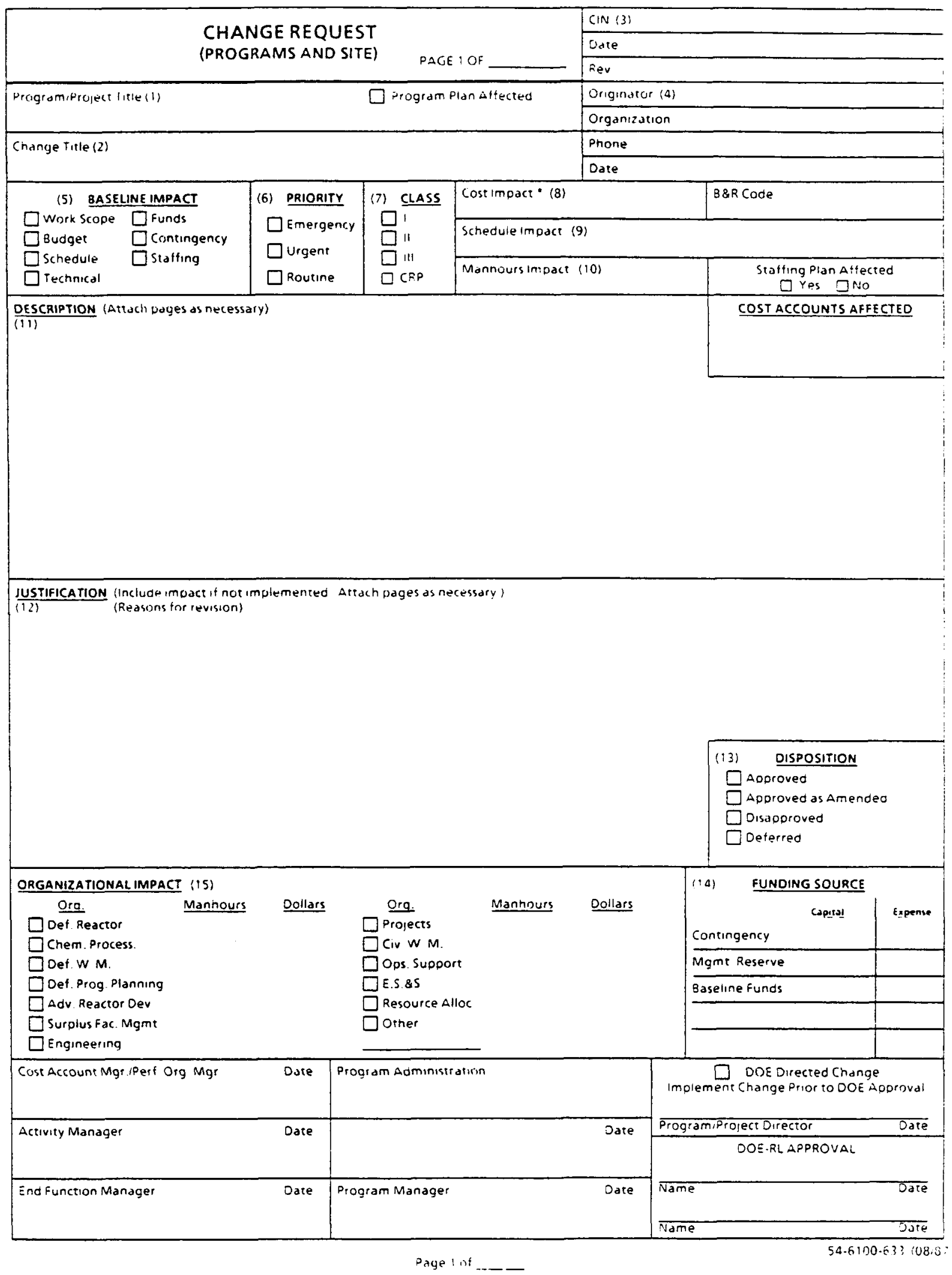


WHC-EP-0388

documented. Based on the impacts of the change, a change classification is assigned that establishes the approval level. The approval level is summarized as follows:

- Class I--Requires approval of Change Control Board

- Class II--Requires approval of Change Evaluation Board

- Class III--Requires approval of the CAM.

\subsection{CHANGE IMPLEMENTATION}

All changes, once properly documented and approved, are incorporated into the affected baseline as quickly as possible. Until all documentation is properly updated, authorization to proceed with a change is not made. Any deviations from this requirement are addressed on a case-by-case basis and are submitted as an emergency change. Permission to proceed in advance of formal change approval for an emergency change requires the same level of authority as that required for the change. All changes require a CR form. The CRs are recorded on a CR $\log$ (Figure 7-3 shows an example log with the type of data required to be tracked), which is updated to reflect the status of the CR as it goes through the approval process. The CAP is then sent to the budget analyst to ensure that changes have been incorporated and the budget analyst will enter the changes into the FDS.

Before the approved change can be incorporated into the CAP, a revised CAA is provided by the WBS activity-level manager. The revised CAA provides guidance to proceed with the approved change, along with the new total budget, schedule constraints, and scope of work, as applicable. A modified budget plan (i.e., BCWS) is developed by the CAM and incorporated into a revised CAP. Revised CAPs and CAAs are approved in the same way as the originals. The program administration or project control organization then updates the baseline logs, schedules, and appropriate data bases (e.g., BCWS time spread, WBS dictionary), and informs the CAM that the revision is now authorized for work accomplishment.

\subsection{MANAGEMENT CONTROL SYSTEM GROUND RULES}

The following ground rules must be followed to ensure that changes comply with the MCS.

- Retroactive changes to schedules or records of BCWS, BCWP, or ACWP for completed or open task packages (a task package that has begun its scheduled work) may not be made, except for the correction of errors and for routine accounting adjustments.

- Once a task package has started, or has reached its scheduled start, no part of its budget may be reassigned to another task package unless the first task package is closed and its remaining scope is reassigned along with the budget. 
$03 / 81,40$

rope 1

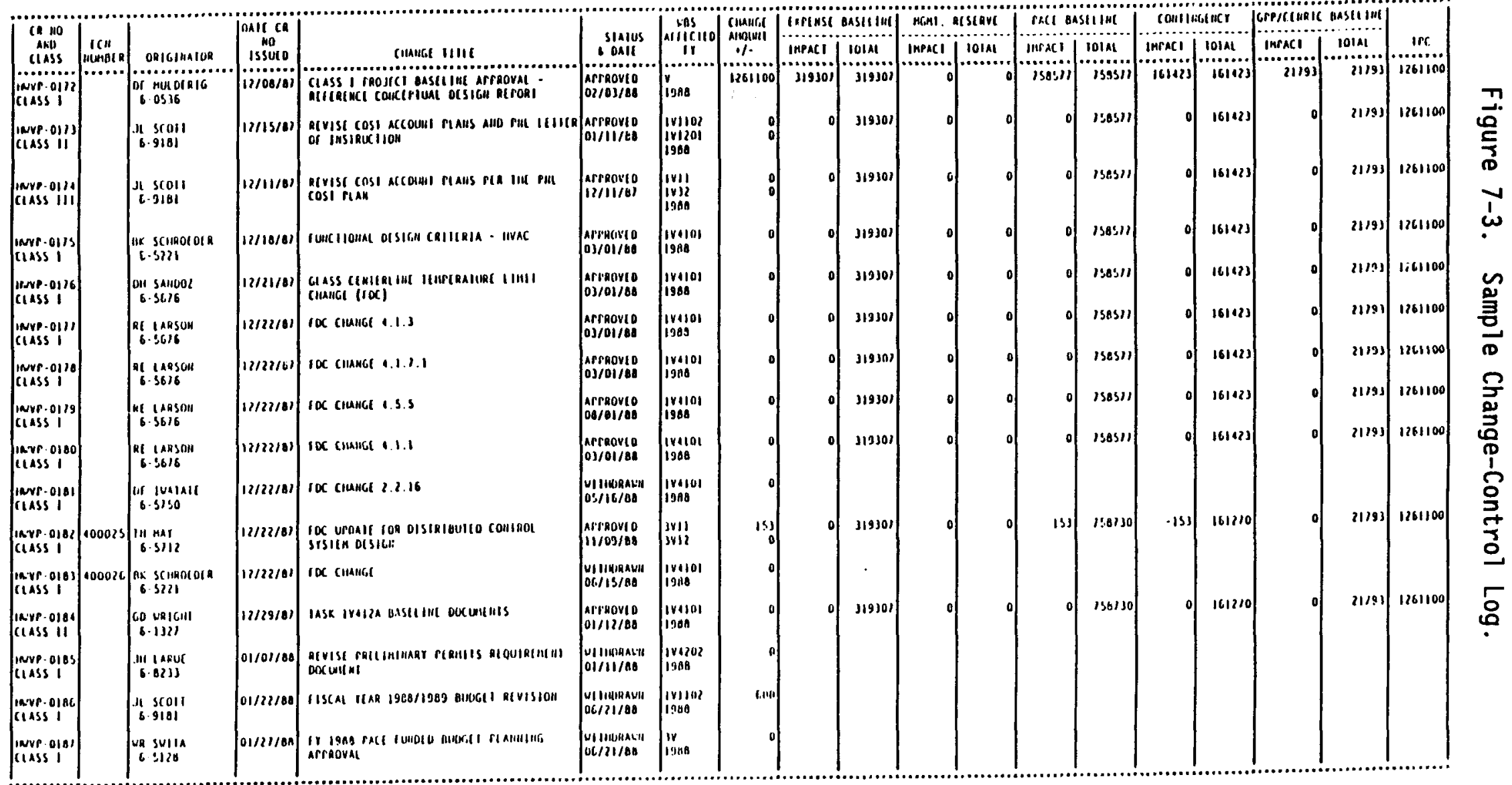


- Scope of work cannot be transferred without transferring the associated budget. Conversely, budget cannot be transferred without transferring the associated scope of work.

- Budget may not be transferred from future work to present work without corresponding formal transfer of the associated work scope. Any BCWS changes to future or unopened work packages may be made within authorizing document constraints.

\subsection{PRODUCTIVITY AND COST EFFECTIVENESS PROGRAM}

Westinghouse Hanford has established the Productivity Improvement and Cost Effectiveness (PRICE) Program as a cost-reduction program. Use of funds resulting from cost savings identified under the PRICE program requires application of the procedures and systems of the MCS. In particular, proposed cost savings are processed through the appropriate program change process for savings affecting one or more programs and through the indirect budget change board for changes affecting overhead or service budgets.

Cost savings proposals are treated as Class I changes requiring DOE-RL approval if they meet the following criteria:

- The change involves a modification or waiver of a DOE policy or requirement.

- The change is so complex or broad that it cannot easily be identified to a budget(s) or requires special adhoc methods for evaluation.

Other cost reduction proposals will be treated as Class II changes. 
WHC-EP-0388

\subsection{SURVEILLANCE}

The objective of surveillance is to ensure that the operating MCS continues to meet the guidelines established in this MCS Description. Surveillance entails a systematic approach to periodic, thorough reviews of MCS operation and maintenance. The major steps in the surveillance process are shown in Figure 8-1. (Reference procedure WHC-CM-2-5, 5.1.) 


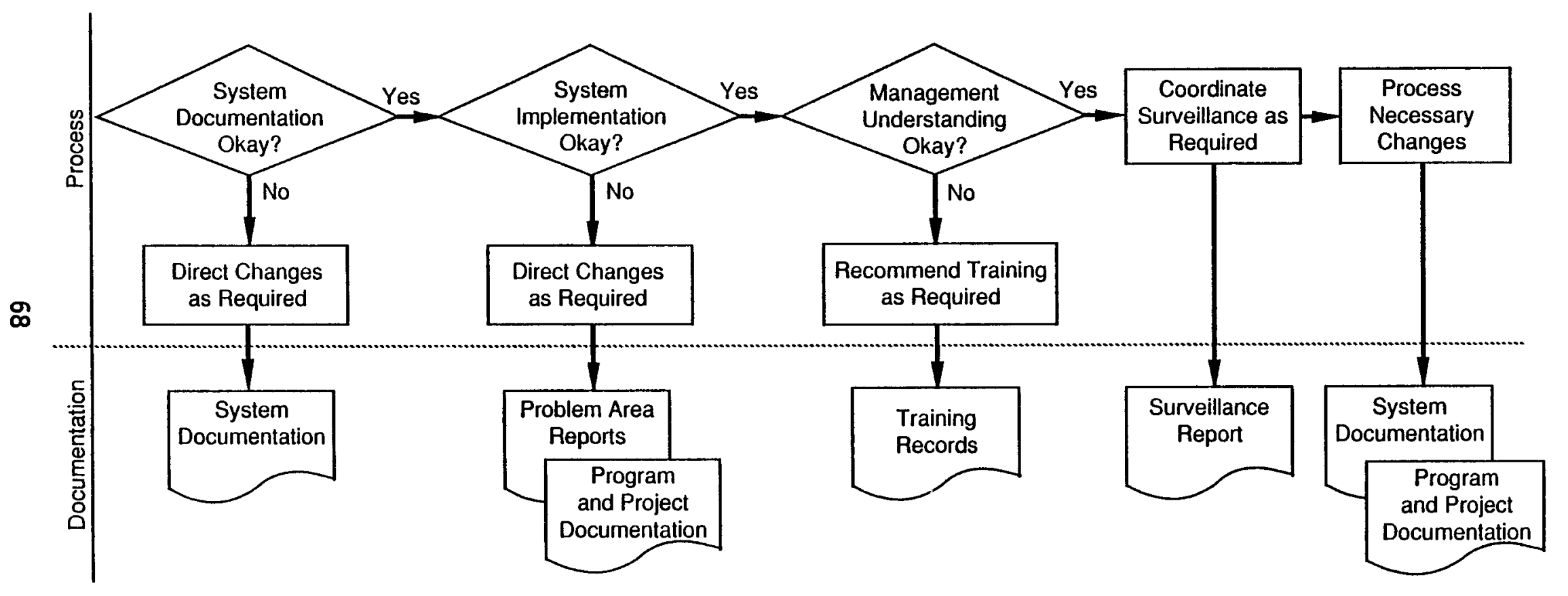

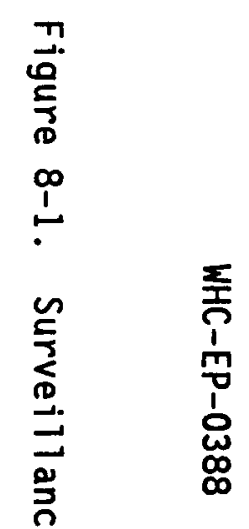

R9006160.4 


\subsection{REFERENCES}

DOE, 1988 (December 21), Cost and Schedule Control Systems Criteria, DOE Order 2250.1C, U.S. Department of Energy, Washington, D.C.

DOE, 1985 (October 15), Uniform Reporting System, DOE Order 1332.1A, U.S. Department of Energy, Washington, D.C.

DOE-RL, 1989 (March 16), Project Management System, U.S. Department of Energy, DOE-RL Order 4700.1, Richland Operations Office, Richland, Washington.

DOE-RL, 1985 (March 27), Cost Estimating, Analysis, and Cost Standardization, DOE Order 5700.3, U.S. Department of Energy, Richland Operations Office, Richland, Washington.

WHC, 1990 (July 24), Management Control System, WHC-CM-2-5, Westinghouse Hanford Company, Richland, Washington. 
WHC-EP-0388

This page intentionally left blank.

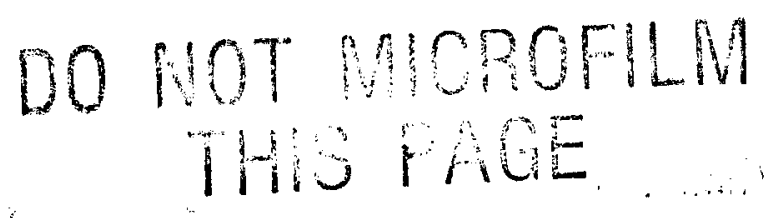


WHC-EP-0388

APPENDIX A

GLOSSARY OF TERMS

$$
\text { A-1/2 }
$$


WHC-EP-0388

This page intentionally left blank.

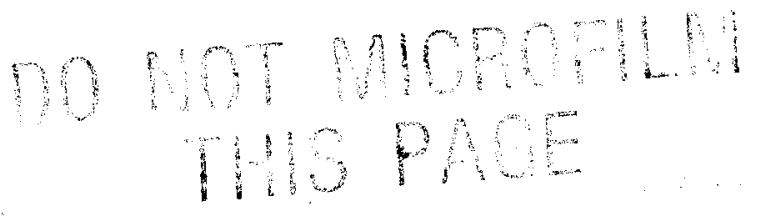


WHC-EP-0388

\section{GLOSSARY OF TERMS}

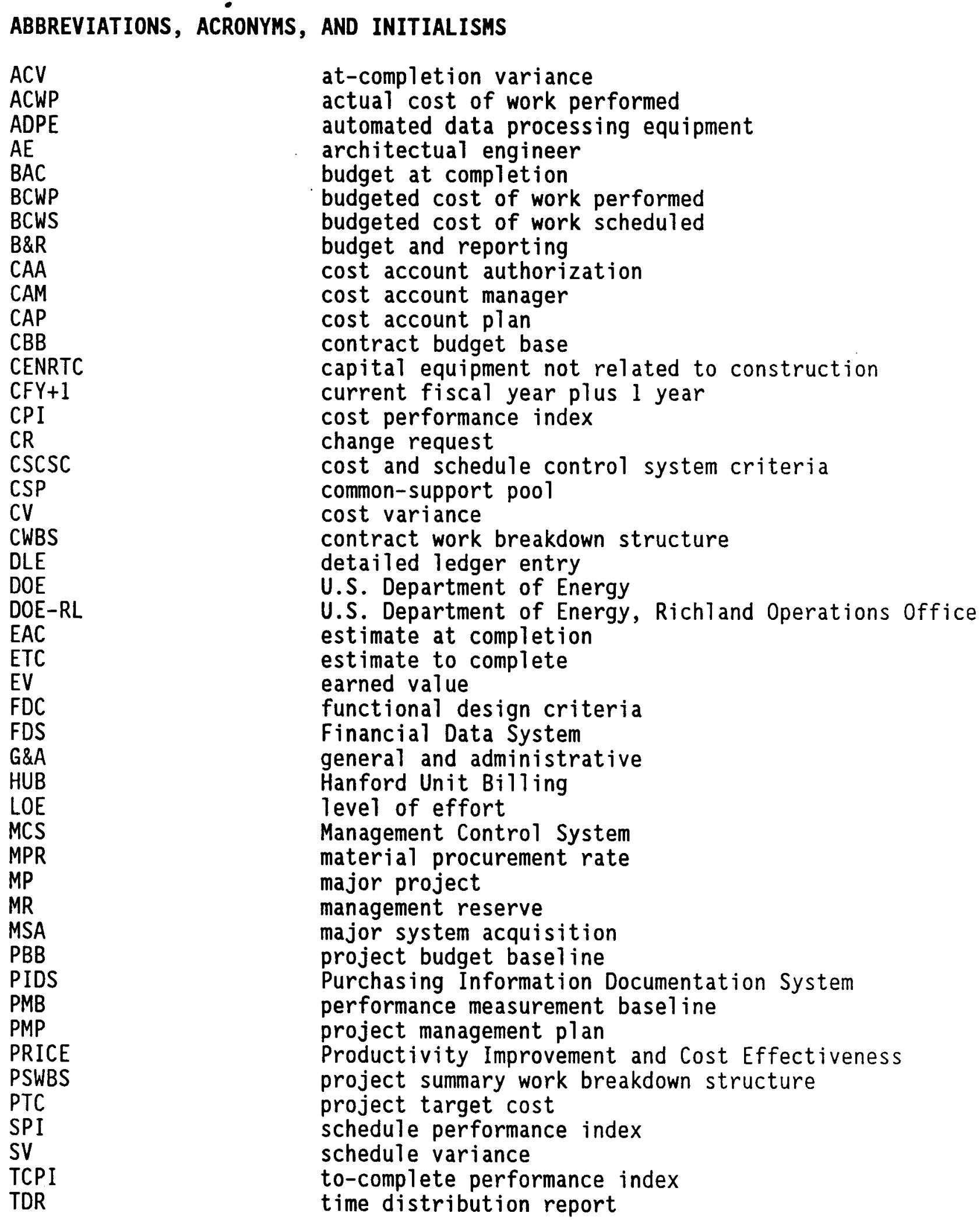


TPCN

TPSI

UB

VAR

WBS

Westinghouse Hanford

WIMS task package control number

Task Package Status Input

undistributed budget

variance analysis report

work breakdown structure

Westinghouse Hanford Company

Warehouse Inventory Management System

\section{DEFINITIONS OF TERMS}

actual cost of work performed (ACWP)--The actual cost incurred and applied or distributed for the work performed within a given time period. It includes all labor categories, material, any other direct costs, subcontract work, and function overhead. Allocated general administrative and service assessment pool charges are also available at appropriate levels.

at-completion variance (ACV)--The difference between the budget at completion (BAC) and the estimate at completion (EAC) for a program and/or project or any element of a program and/or project.

Budget and Funds Control Log--A log kept by the program administration or project control organization defining authorized budget and fund levels and showing any deviations between budget and funds. The $10 \mathrm{~g}$ provides visibility for the need to do replanning or to request additional funds.

budget at completion (BAC)--The sum of budgets for a program and/or project or any element of a program and/or project. For a total project, it is equal to the project baseline budget (PBB).

budgeted cost of work performed (BCWP)--The value for completed work measured in terms of the planned budget for that work. It is synonymous with earned value (EV).

budgeted cost of work scheduled (BCWS)--The time-phased budgeted value of work scheduled to be accomplished over a given time period. The BCWS for a total cost account through its entire period of performance is equal to the BAC for the cost account.

contingency--A special plant and capital equipment budget provision for unknown elements of cost within the defined project scope, such as estimate uncertainties as a result of design evolution, material pricing, labor productivity, crew makeup, estimate error or omission. Contingency is part of the PBB but is not included in the performance measurement baseline (PMB).

contract work breakdown structure (CWBS)--See work breakdown structure (WBS). 
contractor--An entity in the private sector that enters into contracts with the Government. With respect to the Management Control System (MCS), it applies to government-owned, contractor-operated activities that perform work for the U.S. Department of Energy (DOE).

cost account--A management control point for an element of work for which planning is accomplished, performance is measured, and work is controlled. It occurs at that level of a WBS where work can be assigned to one responsible organizational element.

cost account authorization (CAA)--A document used to provide work definition and planning guidance to the cost account manager (CAM) for cost account planning; to obtain agreement among the activity-level, end function level, and cost-account level managers that the planning is satisfactory; and to authorize work to be performed, contingent upon availability of funds.

cost account manager (CAM)--An individual assigned the responsibility for planning a cost account and ensuring that the work is performed in accordance with the plan. Normally, the manager of the responsible organization to which the cost account is assigned.

cost account plan (CAP)--A document used by the CAM for detail planning, time phasing, monitoring, and controlling cost account work.

cost and schedule control system criteria (CSCSC)--The criteria set forth in DOE 2250.1C and its corresponding guides (DOE/MA-0195), D0E/MA-0203, DOE/MA-0221, and DOE/MA-0229) that establish characteristics a contractor's internal MCS must possess to ensure effective planning and control of contract work costs and schedules when applid to designated major projects (MP) and major system acquisitions (MSA).

cost variance (CV)--The difference between BCWP and ACWP (CV = BCWP - ACWP). At any time, it shows whether the work actually performed has cost more or less than the amount budgeted for the same work.

earned value (EV)--The periodic, consistent, and objective measurement of work performed in terms of the budget planned for that work. The EV is synonymous with the BCWP and it is compared to the BCWS to obtain schedule performance and to the ACWP to obtain cost performance.

estimate at completion (EAC)--Direct and indirect cost allocated to the WBS element to date, plus the estimate of costs (direct and indirect) for authorized work remaining (ETC). Authorized work remaining includes any undistributed budget.

estimate to complete (ETC)--The time-phased estimate of costs (direct and indirect) for authorized work remaining. Actual costs (direct and indirect) added to the ETC equals the EAC. 
financial data system (FDS)--Westinghouse Hanford Company automated budget development, performance reporting, and cost collection system that incorporates requirements of the MCS.

level of effort (LOE)--An EV method used for support-type work that does not readily lend itself to measurement of discrete accomplishment or does not directly affect schedule. The BCWP is always equal to BCWS; therefore, there can be no schedule variance (SV).

major projects (MP)--Those projects that are important to DOE program objectives, are of a size and complexity requiring special management attention, and whose total cost ranges from $\$ 50$ to $\$ 200$ million.

major system acquisition (MSA)--Those projects directed at and critical to fulfilling a DOE mission, that entail the allocation of relatively large resources (in excess of $\$ 50$ million in the advanced development phase and in excess of $\$ 100$ million over the life of the project), and warrant special management attention, such as the application of CSCSC.

management reserve (MR)--The portion of the contract's total allocated budget withheld by the contractor for management control purposes, rather than designated for the accomplishment of a specific work element or set of work elements. It is not a part of the PMB, but is included in the PBB.

Milestone Control Log--A log kept of all milestones recorded on the CAAs that serves a control record and change record.

performance measurement baseline (PMB)--The time-phased budget plan against which work performance is measured. It is formed by budgets assigned to scheduled cost accounts. The PMB also includes undistributed budget (UB). The PMB reconciles to the PBB, in that the PMB $p 1$ us MR and contingency equals the PBB.

performance report--A set of standard formatted reports that reflect actual work performance against planned work performance, provide status of the program and/or project baseline, and analyze significant variances.

performing organization--A defined unit within the organizational structure that performs work. Ideally, the responsible organization for a cost account and the performing organization for most of the associated work are the same.

planning package--A logical aggregation of work within a cost account, normally far-term effort that can be identified and budgeted in early baseline planning, but cannot be planned in the detail required for a work package. It is further broken down into one or more task packages as the necessary information becomes available, or at least 1 month before the scheduled start date.

project budget baseline (PBB)--The total allocated budget for a given project. The PBB is equal to the PMB plus the MR and contingency, and is normally synonymous with the total project BAC. 
project management plan (PMP)--A document that defines the project's organization structure, roles and responsibilities, the top-level cost and schedule baselines, and the change control throsholds.

project summary work breakdown structure (PSWBS)--See work breakdown structure (WBS).

reprogramming--A comprehensive replanning of the effort remaining on a program and/or project, usually as a result of (1) an accumulation of significant variances that, when totaled, make the current PMB invalid, or (2) a major change in work scope, schedule, or funding allocation usually resulting in a significant change to the PBB.

responsible organization--A defined element within the contractor's organization structure assigned the responsibility for planning and accomplishment of a cost account. The manager of the responsible organization is normally assigned as the CAM.

schedule variance (SV)--The difference between BCWP and BCWS $(S V=B C W P$ - BCWS). At any time, or for a given period of time, it represents the difference between the planned dollar value of work actually accomplished and the value of the work scheduled to be accompli shed.

significant variance--A cost or schedule variance that exceeds allowable, established thresholds, thereby requiring formal review, analysis, and corrective action.

task package--The lowest level of work planning and the point at which resources are assigned. A task package has the following characteristics:

- Represents manageable units of the work package that in total make up the work scope

- Assigns work to be done by one organization

- Assigns the performance measurement method

- Has scheduled start and completion

- Has a schedule for accomplishment that supports the requirements of higher level schedules.

Task Package Status Input (TPSI)--A monthly formatted status input provided by CAMs, which reflects progress of task packages during the month and is used to calculate BCWP.

undistributed budget (UB)--The budget within the PMB that is not planned as part of a cost account. The UB is normally budget of new work scope that has not been planned to the cost-account level. 
work breakdown structure (WBS)--A product-oriented family tree division of real estate, hardware, software, services, and data products that organize, define, and display all of the work to be performed in accomplishing the program and/or project objectives. Within a MP or MSA the WBS is divided into the following:

- project summary work breakdown structure (PSWBS)--A summary WBS tailored by project management to the specific project, with the addition of the elements unique to the project. Generaliy, the PSWBS will identify project elements through the level necessary to identify customer reporting elements.

- contract work breakdown structure (CWBS)--The complete WBS for a contract developed and used by each contractor or given project in accordance with the project statement of work. It extends the PSWBS to the lowest level for definition and planning of the project work.

Work Breakdown Structure (WBS) Dictionary--The dictionary provides a scope description for each WBS element, with emphasis on clearly defining the content. It is divided into two parts: an index of all WBS elements and individual element description sheets.

work package--A specific scope of work, usually near-term, within a cost account that is made up of task packages. A work package has the following characteristics:

- It represents manageable elements of the cost account, which in total make up the cost account.

- It defines and summarizes the tasks to be performed.

- It is clearly distinguishable from all other work packages. 
DISTRIBUTION

Number of copies

ONSITE

3

U.S. Department of Enerqy. Richland Operations office

R. D. Larson

Public Reading Room (2) Al-65

Westinghouse Hanford Company

R. J. Ausere

G5-08

B. A. Austin

B2-14

D. K. Bailey

S6-08

Q. L. Baird

R2-30

R. E. Barker

T5-08

L. W. Bartholf

H5-60

J. D. Bauer

B3-15

D. L. Becker

B3 -58

J. R. Bell

M. L. Bell

R3-60

G. L. Bennett

T5-50

S. I. Bennion

$\times 0-43$

E. M. Benson

N1 -71

J. D. Berger

T5-09

T. D. Blankenship

LO-18

R. J. Bliss

R1-62

G. R. Board

B3-04

D. M. Bogen

S4-01

M. T. Bouchey

R2-73

D. L. Bouse

R2-40

N. C. Boyter

L4-03

M. K. Britton

R2-52

W. R. Brooksher

B4-54

D. E. Brown

L4-0]

L. C. Brown

A2-78

J. G. Burk

H4 -51

M. J. Byrd

B3-25

M. A. Cahill

G. D. Carpenter

H3-08

R3-46

D. B. Cartmell

H4-15

J. G. Cassady

R2-64

K. L. Chubb

B3-07

G. L. Clogston

L8-10

B. D. Corder

$\mathrm{H} 2-18$

B2-52

J. E. Cottrell

T7 -20

C. M. Cox

$\mathrm{R} 2-28$

H. L. Debban

$\times 0-43$

C. Defigh-Price

B2-20

J. L. Deichman

$\mathrm{HO}-03$ . 
Westinghouse Hanford Company (cont.)

T. L. Denton

G1-74

D. R. Dillie

B3-53

R. R. Disibio

B3-02

W. T. Dixon

B2 -35

B. P. Dole

A2-50

V. R. Dronen

R3 -42

G. T. Dukelow

R2-97

D. S. Dutt

L5-60

R. A. Dutton

B3-06

F. W. Ellis

L6-53

J. H. Ell is

S5-66

T. 0 . El sethagen

A2-50

$D$. W. Engel

ᄂ4-11

R. A. Eschenbaum

S6-11

S. A. Estey

D. L. Fischer

A2-35

A. J. Fisher

Al-05

J. M. Fogle

S1-5I

D. R. Fox

A3-50

J. C. Fulton

Al-10

R. R. Gadd

R2-67

A. D. Gadeken

B3-65

R. G. Gant

B4-52

J. H. Garbrick

L6-18

J. S. Garfield

S4-08

T. E. Gates

R1-16

R. B. Gelman

B] -41

E. W. Gerber

$\mathrm{R} 2-56$

R. L. Gilchrist

L5-62

D. E. Good

L5-63

A. W. Graves

So-97

E. F. Gray

D. J. Green

H5-61

A. Greenberg

J. M. Grover

N2-35

H5-53

M. L. Grygiel

S5-66

S. Guttenberg

L5-55

M. Haas

R. M. Hadley

$56-65$

J. W. Hagan

T5-53

P. S. Hale

Gl -67

W. H. Hamilton

B3-35

E. R. Hamm

R2-40

J. H. Hammond

S2-93

R. E. Harding

B3-03

A3-90

T. J. Harper

GI-56

J. D. Hart

R2-42

A. R. Hawkins

L4-85

J. M. Hawkins

H2-14

D. G. Hay

R2-42

H. W. Heacock

HO-30

W. F. Heine

B2-35 
Westinghouse Hanford Company (cont.)

R. E. Heinman

R3-12

R. L. Hibbard

T2-08

K. L. Hoewing

B3-06

R. W. Hollerman

$\mathrm{H} 2-03$

W. D. Holloman

B3-59

B. A. Holmberg

R2-79

J. J. Holmes

L5-55

J. 0. Honeyman

B1-41

L. C. Hubbard

B4-05

W. F. Irvine

G2-02

G. W. Jackson

R4-01

C. W. Jensen

L4-06

P. D. Jensen

T5-51

C. E. Johnson

A2-90

K. R. Jordan

R2-56

R. G. Joseph

H2- 15

D. P. Kerwick

S5-02

J. A. Kion

T4-10

J. R. Kirkendall

L5-63

K. B. Klos

G6-55

R. L. Kneckt

J. R. Knight

$\mathrm{N} 1-47$

J. M. Knoll

B4-52

R. J. Kobelski

B3-59

H. H. Kohl

LO-24

M. K. Korenko

S1-51

E. J. Kosiancic

B3-08

G. R. Kraemer

SO-61

D. G. Krohn

H5-60

G. L. Kunkle

A3-92

D. A. Lawrence

S5-75

F. D. Lee

S1-01

W. D. Leggett

B4-40

L. S. Legowik

L5- 04

R. E. Lerch

L4-89

E. F. Loika

B2 -35

R. A. Lujan

L4-73

C. K. Macleod

NI-22

M. K. Mahaffey

B3-15

D. E. Mahagin

L4-73

R. P. Marshall

H4-21

R. T. Martell

T5-52

D. E. Mcelroy

H3-06

H. E. McGuire

A3-92

B2-35

C. A. Meldrom

T5- 02

F. F. Melton

H3-08

G. A. Meyer

R2-28

R. J. Meyer

GI -56

J. C. Midgett

B. J. Miller

G. J. Miskho

RI-48 
Westinghouse Hanford Company (cont.)

G. Mitchell

$\mathrm{R} 2-50$

R. D. Moerman

B5-20

B. C. Moravek

B3-31

G. H. Moulthrop

B3-25

S. P. Muller

B2 -67

D. J. Newl and

$\mathrm{N} 1-35$

R. C. Nichols

B3-01

F. J. Orsag

J. F. Oswaid

$52-62$

D. G. Panther

$\times 0-56$

M. A. Payne

S6-23

P. A. Peacock

S5-66

J. 0. Perkins

B3 -19

L. H. Peterson

A2-50

R. W. Powe 11

B3 -53

P. R. Praetorius

L5-55

J. G. Propson

S1-56

R. J. Pyzel

R2-18

D. K. Quigley

$\times 0-42$

S. A. Rasp

GI-56

J. J. Ratcliffe

B3-26

R. E. Raymond

B5-25

G. G. Renfro

RI-80

L. H. Rice

B4-65

R. C. Roal

$\mathrm{N} 1-36$

W. E. Ross

S6-08

W. G. Ruff

S5-66

D. E. Sandberg

R2-53

E. R. Saxon

A4-25

A. R. Schade

SO-46

W. J. Schl auder

B1-35

J. P. Schmidt

G4-02

M. R. Schmidt

X0-41

U. M. Schroeder

A3-93

P. Segall

B4-50

L. K. Severud

B4-53

W. D. Shaw

H5-60

W. F. Sheely

B2-52

R. 0. Shelby

B4-03

R. L. Sherman

S2-01

$\times 0-34$

H. A. Sieber

B2-67

D. E. Simpson

B3-51

G. E. Skaare

S6-61

R. C. Skelton

A2-35

S. A. Slinn

$\times 5-06$

R. G. Slocum

R2-34

C. H. Smith

B2-66

J. H. Smith

G1-56

R. A. Smith

G6-02

J. R. Sorensen

$\mathrm{H} 2-23$

R. J. Sponseller G1-20

W. R. Sporich

A2-21 
Westinghouse Hanford Company (cont.)

$\begin{array}{ll}\text { G. A. Stanton } & \text { S4-65 } \\ \text { F. O. Strankman } & \text { L4-05 } \\ \text { R. M. Suyama } & \text { L7-03 } \\ \text { D. J. Swaim } & \mathrm{N} 2-51 \\ \text { J. A. Swenson } & \mathrm{N} 1-34 \\ \text { C. E. Swift } & \mathrm{B} 4-09 \\ \text { J. D. Thomson } & \mathrm{H} 5-01 \\ \text { V. R. Treadway } & \mathrm{Al}-60 \\ \text { J. W. Tritz } & \mathrm{B} 3-67 \\ \text { G. E. Vansickle } & \mathrm{R} 1-15 \\ \text { T. C. Varljen } & \mathrm{B} 3-65 \\ \text { T. B. Veneziano } & \mathrm{B} 2-35 \\ \text { E. P. Vodney } & \mathrm{B} 3-50 \\ \text { E. C. Vogt } & \mathrm{T} 5-50 \\ \text { J. L. Waite } & \mathrm{B} 2-35 \\ \text { A. E. Waltar } & \mathrm{H}-32 \\ \text { V. R. Weil } & \mathrm{G} 4-04 \\ \text { E. L. Wells } & \mathrm{A} 2-35 \\ \text { W. P. Whiting } & \mathrm{B} 3-30 \\ \text { J. C. Wiborg } & \mathrm{R} 3-09 \\ \text { S. A. Wiegman } & \mathrm{B} 2-19 \\ \text { M. J. Wiemers } & \mathrm{NI}-42 \\ \text { G. R. Wilson } & \mathrm{B} 1-41 \\ \text { W. G. Wilson } & \mathrm{B} 3-55 \\ \text { G. M. Wise } & \mathrm{B} 3-70 \\ \text { D. D. Wodrich } & \mathrm{R} 2-23 \\ \text { R. D. Wojtasek } & \mathrm{L} 4-92 \\ \text { H. H. Yoshikawa } & \mathrm{B} 1-41 \\ \text { M. W. Young } & \mathrm{H} 5-58 \\ \text { Central Files (2) } & \mathrm{L} 8-04 \\ \text { Publications Services (3) } & \mathrm{R} 1-08\end{array}$

Publications Services (3) Rl-08

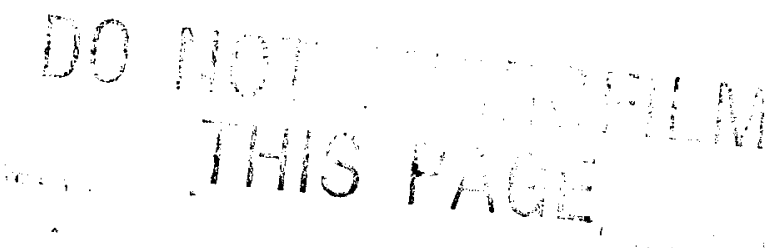

